\title{
A physically based model of the year-round surface energy and mass balance of debris-covered glaciers
}

\author{
Yves LEJEUNE, ${ }^{1}$ Jean-Maxime BERTRAND, ${ }^{1,2}$ Patrick WAGNON, ${ }^{2}$ Samuel MORIN ${ }^{1}$ \\ ${ }^{1}$ Météo-France/CNRS, CNRM-GAME URA 3589, CEN, Grenoble, France \\ E-mail: yves.lejeune@meteo.fr \\ ${ }^{2}$ IRD/UJF-Grenoble 1/CNRS/G-INP, LGGE UMR 5183, LTHE UMR 5564, International Centre for Integrated Mountain \\ Development, Kathmandu, Nepal
}

\begin{abstract}
Debris-covered glaciers respond to atmospheric conditions in different ways from debrisfree glaciers, due to the presence of debris at the surface during the ablation season and at the snow/ice interface during the accumulation season. Understanding the response of debris-covered glaciers to a variety of meteorological conditions in a physically sound manner is essential to quantify meltwater discharge and to predict their response to climate change. To tackle this issue, we developed the CrocusDEB model as an adaptation of the detailed snowpack model Crocus, to simulate the energy and mass balance of debris-covered glaciers, including periods when debris is covered by snow. Crocus-DEB was evaluated with data gathered during a field experiment using artificial debris covering the snowpack at Col de Porte, France, with very good results in terms of conductive heat flux, both at the surface and at the interface between the debris and the underlying dense snow taken as a surrogate for ice, with and without snow overlying the debris. The model was also evaluated using field data from the debriscovered glacier Changri Nup, Nepal, Himalaya. This paper introduces the design of the model, its performance and its ability to explore relationships between model parameters, meteorological conditions and the critical debris thickness.
\end{abstract}

\section{INTRODUCTION}

Debris-covered glaciers are a common glacier type in alpine environments, especially in the high-relief Hindu KushHimalaya $(\mathrm{HKH})$ range (e.g. Moribayashi and Higuchi, 1977; Benn and others, 2003), where most of the ablation areas are partly or even totally covered with supraglacial debris. Given that the $\mathrm{HKH}$ region is the largest ice mass outside the polar regions (Dyurgerov and Meier, 2005) and the most populated on Earth, it is potentially one of the most critical parts of the world in terms of the social and economic impacts of glacier shrinkage (Barnett and others, 2005; Immerzeel and others, 2010; Bolch and others, 2012). Predicting the evolution of $\mathrm{HKH}$ glaciers is therefore a key issue as their melting may (1) negatively affect regional water supply in the next decades (Barnett and others, 2005; Immerzeel and others, 2010), (2) significantly contribute to ongoing sea-level rise (Kaser and others, 2006) and (3) increase natural hazards linked to glaciers, especially glacial lake outburst floods (e.g. Mool and others, 2001). Recent research has not reached a consensus, in terms of the role played by debris at the surface, about glacier mass balance in the $\mathrm{HKH}$ and the response of debris-covered glaciers to climate change (Scherler and others, 2011; Kääb and others, 2012). The role of debris has hitherto been neglected in predictions of future water availability (Immerzeel and others, 2010) or sea-level rise at the global scale.

A supraglacial debris layer significantly influences the melting of the underlying ice and has a specific surface energy balance very different to that of debris-free glaciers. The main physical characteristics of a debris layer (in contrast to snow or ice) are its thermal conductivity, its albedo and the fact that its temperature can rise above 273.15 K (Nicholson and Benn, in press). The debris has a conflicting effect on the underlying ice through a reduced albedo, dominant for thin debris layers, and increased thermal shielding, dominant for thicker debris cover. Østrem (1959) established empirical relationships between supraglacial debris thickness and ice-melt rates, and introduced the concept of critical debris thickness, below which ice ablation is enhanced and above which it is reduced, compared to a debris-free surface. This pattern has been confirmed in numerous subsequent studies (e.g. Loomis, 1970; Mattson and others, 1993; Conway and Rasmussen, 2000; Kayastha and others, 2000; Nicholson and Benn, in press), which further show that the critical thickness varies under the influence of debris lithology and local climate.

In order to estimate the mass balance of debris-covered glaciers, empirical methods, such as the degree-day approach, have been applied to a few glaciers (Kayastha and others, 2000), but they are too site-specific and too dependent on the conditions prevailing during the measurement period to allow any reliable spatial or temporal extrapolation (e.g. Hock, 2003; Nicholson and Benn, 2006). To predict both short-term melt rates in response to meteorological conditions and long-term glacier ablation regimes, which influence the dynamic response of debris-covered glaciers to climate forcing, a physically based ablation model is needed (Nicholson and Benn, 2006). Consequently, an effort has recently been made by glaciologists to develop physically based energy-balance models to assess how the debris layer affects glacier melt rates (Nicholson and Benn, 2006; Reid and Brock, 2010; Reid and others, 2012). The numerical models introduced by Nicholson and Benn (2006) and Reid and Brock (2010) were developed only for the ablation season, assuming that the ice/debris interface always remains at the melting point. This assumption is sometimes not true during clear nights where refreezing is efficient, and is obviously not fulfilled outside the ablation season. Contrary to the model of Nicholson and Benn (2006), which operates at a daily time resolution, assuming a linear temperature 


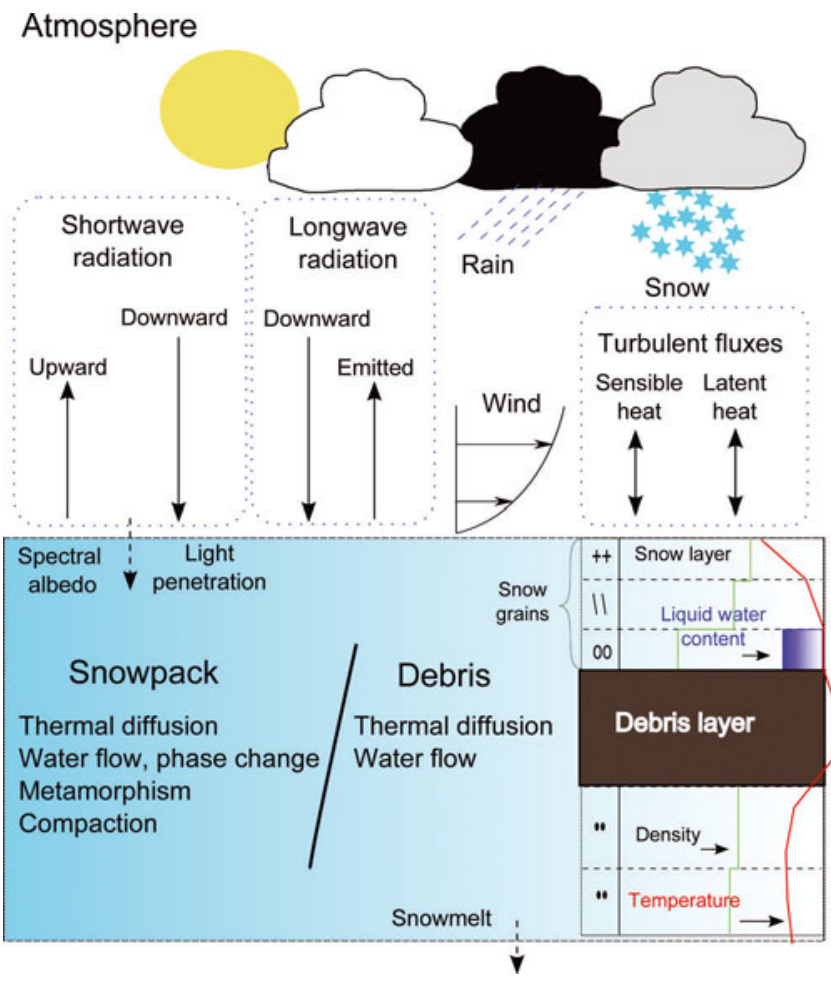

Fig. 1. Overview of the processes accounted for by the Crocus-DEB snowpack model, showing the possible presence of a debris layer sandwiched between snow or ice below and a transient snowpack on top (adapted from Vionnet and others, 2012).

profile between the upper and lower surfaces of the debris layer, the model of Reid and Brock (2010) fully solves the heat conduction equation through the debris using a timestep of 1 hour. Working at such a short timescale is necessary to properly simulate the processes responsible for the diurnal melting of the underlying ice, adequately accounting for the competition between the surface energy budget and thermal diffusion through the debris. The model of Reid and Brock (2010) is thus able to reproduce the existence of the critical debris thickness initially described by Østrem (1959). Here, we present a physically based model able to simulate mass and energy fluxes of a debris-covered glacier all year round, i.e. able to calculate the temperature of the ice/debris interface, to simulate the ice melt and to manage the presence of a transient snowpack on top of the debris. This model is called Crocus-DEB, because it stems from the detailed snowpack model (Brun and others, 1989, 1992) which has been used in the past for distributed simulations of glacier mass balance (Gerbaux and others, 2005; Lejeune, 2009; Dumont and others, 2012). The suffix '-DEB' used to discriminate between the standard and modified versions of Crocus refers to the first syllable of the word 'debris', consistent with Reid and Brock (2010). The detailed snowpack model Crocus explicitly evaluates mass and energy exchange between the snowpack and the low-level atmosphere as a function of meteorological conditions. In Crocus-DEB, the debris layer has been inserted as stacks of snow layers, featuring physical properties corresponding to the debris.

In this study, we first give a detailed description of the model, focusing on the adaptations made to include debris layers in the snowpack. Second, we present the results of simulations performed at the instrumented experimental site Col de Porte (Chartreuse range, French Alps, 1325 ma.s.I.; $45^{\circ} 17^{\prime} \mathrm{N}, 05^{\circ} 45^{\prime} \mathrm{E}$ ), where we artificially poured a $4 \mathrm{~cm}$ and a $15 \mathrm{~cm}$ thick debris layer over seasonal snow cover in the middle of winter 2011, to quantify the effect of the debris over the snowmelt, thereby providing appropriate driving and evaluation data to inform and test the Crocus-DEB model. Third, the performance of the model is also evaluated using a comprehensive meteorological and glaciological dataset obtained on a Nepalese debris-covered glacier, Changri Nup Glacier (5360 ma.s.I.; $27^{\circ} 59^{\prime} \mathrm{N}, 86^{\circ} 47^{\prime} \mathrm{E}$ ), between November and December 2010. In the final sections we critically discuss the performance of the model and show how it can be used to explore the relationships between the critical debris thickness and the meteorological and environmental conditions of a given glacier.

\section{MATERIAL AND METHODS Model description}

In simple terms, the Crocus-DEB model was developed from the multilayer Crocus snowpack model, building on the idea that a debris layer can be viewed as a snow layer featuring different physical properties. Below, we briefly recall the main characteristics of the Crocus snowpack model which are relevant to the description of Crocus-DEB.

\section{Brief overview of the Crocus snowpack model}

Crocus is a one-dimensional, multilayer, physically based snowpack model that simulates in detail the time evolution of the physical properties of layers making up the snowpack, solely driven by meteorological conditions at the surface (air temperature, wind speed, relative humidity, incoming longwave and shortwave radiation, snowfall and precipitation rate). For each numerical snow layer, $i$, within the snowpack, the model prognostic variables are temperature, $T(i)$ $(\mathrm{K})$, dry density, $\rho(i)\left(\mathrm{kg} \mathrm{m}^{-3}\right)$, i.e. the density of the ice matrix, thickness, $\mathrm{d} z(i)(\mathrm{m})$, liquid water content, $w(i)$ $\left(\mathrm{kg} \mathrm{m}^{-3}\right)$, snow age (days since snowfall) and grain-type properties. The latter are described by four empirical variables (dendricity, sphericity, size and metamorphic state) representing the snow microstructure. More details on the variables used to describe the snow layers in Crocus are given by Bouilloud and Martin (2006), Willemet (2010) and Vionnet and others (2012). The energy budget of each snow layer, $i$, is written as follows:

$$
\begin{gathered}
\frac{\partial}{\partial t}\left(\rho(i) C_{p}(i) \mathrm{d} z(i) T(i)+L_{\mathrm{f}} w(i)\right)= \\
\begin{cases}Q_{\mathrm{c}}(i)+L_{\mathrm{f}} W_{\mathrm{p}}+S_{\mathrm{abs}}(i)+L_{\mathrm{net}}+H+\mathrm{LE}+P & \text { (surface) } \\
Q_{\mathrm{c}}(i)+L_{\mathrm{f}} W+S_{\mathrm{abs}}(i) & \text { (internal layer) } \\
Q_{\mathrm{c}}(i)+L_{\mathrm{f}} W+S_{\mathrm{abs}}(i)+Q_{\mathrm{g}} & \text { (basal layer) }\end{cases}
\end{gathered}
$$

where $C_{p}(i)$ is the specific heat capacity of ice, depending on temperature, and $L_{f}$ is the latent heat for ice fusion $\left(3.33 \times 10^{5} \mathrm{~J} \mathrm{~kg}^{-1}\right)$. On the right-hand side of the equations, $W_{\mathrm{p}}$ and $W$ represent the liquid water input through rainfall or percolation, respectively. $S_{\text {abs }}(i)$ represents the fraction of incoming shortwave radiation absorbed by layer $i, L_{\text {net }}$ is the net longwave radiation flux, $H$ and LE are the turbulent fluxes for sensible and latent heat, respectively, $P$ is the sensible heat flux due to precipitation, $Q_{\mathrm{c}}(i)$ represents the divergence of the conduction flux within layer $i$ and $Q_{g}$ is the basal heat flux. Figure 1 provides an overview of the different processes accounted for by the Crocus snowpack model. 
The computation of energy fluxes within and at the boundaries of the snowpack by Crocus has been described extensively in previous publications (e.g. Brun and others, 1989, 1992; Martin and Lejeune, 1998; Willemet, 2010; Vionnet and others, 2012) and is not repeated here.

\section{From Crocus to Crocus-DEB}

Debris-covered glaciers are modeled as a vertical stack of ice, debris and a potentially developing snowpack at the surface. In this regard, the basic principles of Crocus, i.e. the time evolution of the physical processes of a snowpack consisting of several numerical layers, remain unchanged. We describe below the handling of debris layers by CrocusDEB, including the simplifying hypotheses made.

Variables. To differentiate between numerical layers consisting of debris and those of snow and ice, we use an arbitrarily out-of-range value for one of the prognostic variables used by Crocus to handle snow metamorphism (namely, the variable representing either sphericity or grain size). The only true prognostic variable considered for a debris layer is its temperature. In contrast to a snow or ice layer, the temperature of a debris layer can take values $>273.15 \mathrm{~K}$. Debris layers are attributed a given thickness, density, thermal conductivity and specific heat capacity. These properties remain constant throughout a given simulation. In this work, all the numerical layers making up the debris cover were attributed the same physical properties, but this is not imposed by the model structure. We further hypothesize that the liquid water content of debris layers is always zero, implying that liquid water percolation through the debris is instantaneous and that phase changes do not occur in the interstitial volume in the debris layers.

Processes. When there is a debris layer at the surface, the computation of the surface energy budget is carried out in a different way to the case where snow is present at the surface. When debris is present at the surface, different values than those for snow are used for the thermal emissivity, $\varepsilon$, roughness length, $z_{0}$, and spectral albedo. The spectral absorption coefficient of the debris is considered infinite, i.e. all of the net shortwave radiation budget is affected to the uppermost debris layer. The thermal emissivity of the debris, $\varepsilon_{d}$, is kept constant. The spectral albedo of the debris is fixed throughout a given simulation. The sensible heat flux, $H$, is computed similarly to snow; however the debris can be attributed a different roughness length, $z_{0}$. The latent heat flux, LE, is zero because the debris is considered to be always dry. Liquid water from rainfall is supplied to the uppermost debris layer. The corresponding heat flux is computed similarly to the rainon-snow case (i.e. rainfall temperature is taken equal to air temperature) (Brun and others, 1989, 1992; Vionnet and others, 2012). For the case of snowfall on top of the debris (in a similar way to how Crocus handles snowfall on the ground) a snow cover may or may not develop, depending on the thermal state of the debris. When the debris temperature is below the melting point for ice, a snow cover develops on top of the debris. For higher debris temperatures, development of a snow cover depends on the balance between the heat content of the debris and the falling snow.

When debris is covered by snow, all surface fluxes are computed similarly to the standard Crocus simulation. We use the parameterization of snow albedo introduced by Lejeune and others (2007), which serves to lower albedos, $\alpha_{\mathrm{sd}}$, of the snowpack under a given critical thickness:

$$
\alpha_{\mathrm{sd}}(j)=F_{\alpha} \alpha_{\mathrm{s}}(j)+\left(1-F_{\alpha}\right) \alpha_{\mathrm{d}}(j)
$$

where $\alpha_{\mathrm{d}}(j)$ and $\alpha_{\mathrm{s}}(j)$ are the albedo of debris and snow, respectively, in a given spectral band $j . F_{\alpha}$ is a weighting function defined as

$$
F_{\alpha}=\min \left[1,\left(\frac{h_{\mathrm{sd}}}{h_{\mathrm{sd}}^{\star}}\right)^{x}\right]
$$

where $h_{\text {sd }}$ is the total snow depth over the debris, $h_{\text {sd }}^{\star}$ is the critical snowpack thickness under which the debris has an impact on the snowpack albedo $\left(h_{\mathrm{sd}}^{\star}=0.1 \mathrm{~m}\right)$ and $x$ is an empirical coefficient ( $x=0.33$ ) (Lejeune and others, 2007). This approach allows us to account for the fact that a thin snowpack on top of the debris cover or on top of the ground is influenced by the underlying absorbing surface, effectively lowering its albedo, and also represents the fact that thin snowpacks are often uneven and patchy, which tends to accelerate their melting.

Handling of numerical layers. Crocus features an evolved scheme to dynamically adapt the vertical grid mesh to the snowpack stratification (Brun and others, 1992; Willemet, 2010; Vionnet and others, 2012), leading to automated splitting and aggregating of the numerical snow layers during a model run, depending on the similarity of their physical properties and on the vertical discretization of the snowpack. This feature is switched off for debris layers, i.e. the latter do not undergo any splitting/aggregation throughout a given model run, and keep a constant thickness. The thickness of the numerical debris layers has to be chosen sufficiently small to accurately solve the heat diffusion equation, with a minimum imposed by the numerical scheme and the timestep of the model. A good compromise was found to be a numerical debris-layer thickness of $1 \mathrm{~cm}$ and an internal model time-step of $15 \mathrm{~min}$. In this work, the debris cover was split into as many $1 \mathrm{~cm}$ thick layers as necessary. Note that the thickness of each debris-cover layer can be set individually, and can be adapted depending on the application.

Below-debris temperature. The reference implementation of Crocus-DEB solves the heat diffusion equation (including the phase change in snow and ice) through the whole snow/ debris/ice continuum. However, for the purpose of comparing Crocus-DEB with previous models of debris-covered glaciers assuming that ice below the debris is at the melting point (e.g. Nicholson and Benn, 2006; Reid and Brock, 2010), a modified version of Crocus-DEB was developed in which the temperature of sub-debris layers is forced to the melting point. At each time-step, the temperature of belowdebris layers is raised to the melting point, and the corresponding amount of energy artificially added to the system is recorded. This model version is referred to as Crocus-DEB $\mathrm{m}_{\mathrm{m}}$ below, for the sake of brevity.

\section{Field and numerical experiments at Col de Porte, France}

\section{Field experiment}

The research station Col de Porte (CDP) was used to test and evaluate Crocus-DEB. The CDP experimental snow and meteorological station has been recording the physical properties of the seasonal snowpack since 1959, along with the meteorological conditions. In addition to a detailed description of the site, Morin and others (2012) provide a quality-controlled snow and meteorological dataset spanning the period 1 August 1993 to 31 July 2011 at the site, at 


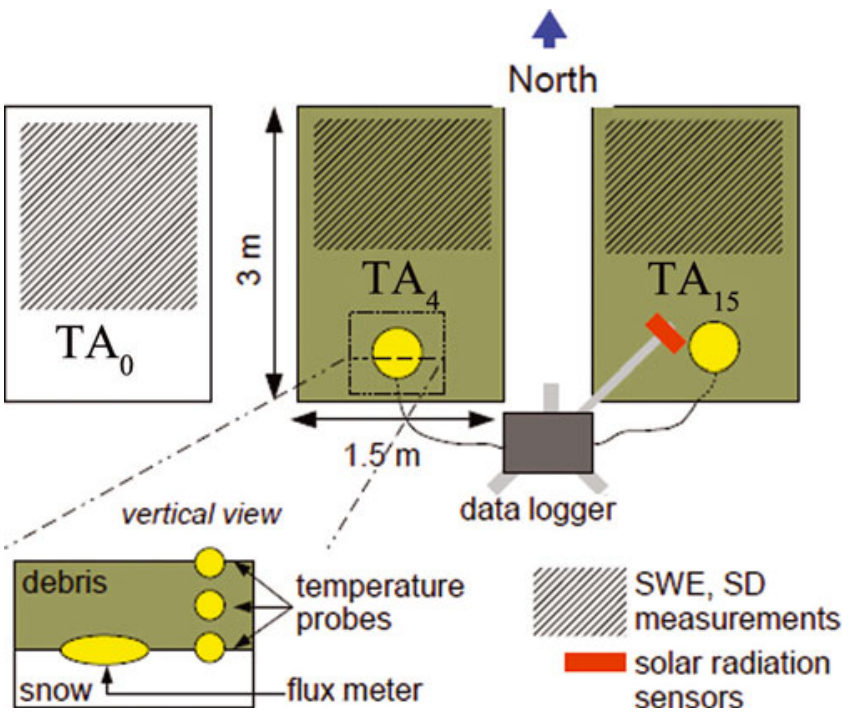

Fig. 2. Schematic view of the experimental set-up at Col de Porte. The two areas with artificial debris thicknesses of 4 and $15 \mathrm{~cm}$, referred to as $\mathrm{TA}_{4}$ and $\mathrm{TA}_{15}$, respectively, are displayed beside the debris-free area, denoted $\mathrm{TA}_{0}$, which in practice corresponded to the regular snow observations area at CDP (Morin and others, 2012).

hourly time-steps, which includes the four components of the surface radiative balance, air temperature and relative humidity, wind speed and direction, precipitation (amount and phase), snow depth and snow water equivalent (SWE), and surface temperature. In addition, at weekly time resolution, in situ snow-pit observations are manually performed at three locations within the field site to measure the SWE, as well as the vertical profile of the physical properties of the snowpack (grain type, density, temperature, liquid water content). Due to differential shading and occasional snowdrift, the snowpack can be spatially heterogeneous (Morin and others, 2012). Nevertheless, the whole area is considered here as the reference debris-free test area $(\mathrm{TA}), \mathrm{TA}_{0}$, for our experiment.

Between February and April 2011, inside the CDP experimental field, a dedicated field experiment was carried out to investigate the impact of a well-characterized debris cover on the underlying snowpack, and to provide data to drive and evaluate the model. The seasonal snowpack was used as a surrogate for the ice mass underlying the debris in the case of a real debris-covered glacier. The gravels were deposited on top of the snowpack on 1 February 2011 at 12:00. One of the two test areas of $1.5 \mathrm{~m} \times 3 \mathrm{~m}$ was covered with a $4 \mathrm{~cm}$ thick layer, the other with a $15 \mathrm{~cm}$ layer; these 'debris-like' layers consisted of rounded gravel (mixed rock types including igneous, sedimentary and metamorphic rocks extracted from the Isère river in a quarry near Grenoble, France) with a density of $1460 \mathrm{~kg} \mathrm{~m}^{-3}$ and a bead size ranging from 10 to $20 \mathrm{~mm}$. These two test areas are referred to hereafter as $\mathrm{TA}_{4}$ and $\mathrm{TA}_{15}$, respectively, and their results are compared with those of the reference debris-free area, $\mathrm{TA}_{0}$. Figure 2 provides an overview of the experimental set-up. Sensors were placed to continuously measure the temperature at the bottom, in the middle and at the top of artificial debris layers (Pt100 temperature probes), and the conductive heat flux at the bottom of the debris (Hukseflux HFP01). In addition, incoming and reflected shortwave radiation were measured on top of $\mathrm{TA}_{15}$ with a pyranometer (Hukseflux NR01). From 8 February 2011 at 16:00 to 7 April 2011 at 08:00, approximately weekly visits were made to the study site to carry out manual measurements of snow depth and SWE above and below the artificial debris, as well as on $\mathrm{TA}_{0}$. Manual measurements were carried out on one side of the TA, while automated measurements were carried out on the opposite side, to minimize disturbance to the continuous measurements. Manual snow corings providing the sum of SWE below and above the debris were performed on 8, 11 and 24 February and 21, 25 and 29 March 2011. Measurements limited to the upper snow layers above the debris were additionally carried out on 24 February and 11 and 15 March 2011.

\section{Numerical simulations}

The Crocus-DEB model is driven using the same meteorological forcing as Crocus (Brun and others, 1992; Willemet, 2010), i.e. hourly records of air temperature, $T_{\mathrm{a}}$, relative humidity, $H_{a}$, incoming longwave and shortwave radiation, $L_{\text {in }}$ and $S_{\text {in, }}$, wind speed and snow- and rainfall. Model simulations were carried out on $\mathrm{TA}_{0}, \mathrm{TA}_{4}$ and $\mathrm{TA}_{15}$, to numerically reproduce the conditions of the field experiment held at CDP. The values for roughness length, $z_{0, s}$, and thermal emissivity, $\varepsilon_{\mathrm{s}}$, for snow were the usual values of $0.004 \mathrm{~m}$ and 1.0 , respectively. The thermal emissivity, $\varepsilon_{\mathrm{d}}$, thermal conductivity, $k_{\mathrm{d}}$, and specific heat, $C_{p, \mathrm{~d}}$, for the debris were assigned the values $0.95,0.7 \mathrm{~W} \mathrm{~m}^{-1} \mathrm{~K}^{-1}$ and $950 \mathrm{Jg}^{-1} \mathrm{~K}^{-1}$, consistent with Reid and Brock (2010) for their study on Miage glacier, Italy. The values of density, $\rho_{\mathrm{d}}$, and albedo, $\alpha_{\mathrm{d}}$, of the debris were determined experimentally and the obtained values of $1460 \mathrm{~kg} \mathrm{~m}^{-3}$ and 0.2 , respectively, were used for the numerical simulations. The value of the roughness length when debris is at the surface, $z_{0, d}$, was set to a value of 0.012 , which is higher than that of snow but takes into account the fact that the test areas were surrounded by snow. Given that turbulent heat fluxes at the surface/atmosphere interface operate over spatial scales of a few metres at least, it was necessary to account for spatial heterogeneity of the surface in setting the $z_{0, d}$ value. Nevertheless, results were not significantly modified when the $z_{0, d}$ value was varied within a reasonable range. The main adjustable parameters used for the simulation at CDP are summarized in Table 1.

Table 1. Values of the main adjustable parameters for the Crocus-DEB numerical simulation at Col de Porte and Changri Nup Glacier

\begin{tabular}{|c|c|c|c|c|c|c|c|c|}
\hline & $\varepsilon_{\mathrm{s}}$ & $\begin{array}{c}z_{0, \mathrm{~s}} \\
\mathrm{~m}\end{array}$ & $\varepsilon_{\mathrm{d}}$ & $\begin{array}{c}\rho_{\mathrm{d}} \\
\mathrm{kg} \mathrm{m}^{-3}\end{array}$ & $\alpha_{\mathrm{d}}$ & $\begin{array}{c}k_{\mathrm{d}} \\
\mathrm{W} \mathrm{m}^{-1} \mathrm{~K}^{-1}\end{array}$ & $\begin{array}{c}C_{\mathrm{p}, \mathrm{d}} \\
\mathrm{J} \mathrm{kg}^{-1} \mathrm{~K}^{-1}\end{array}$ & $\begin{array}{c}z_{0, d} \\
m\end{array}$ \\
\hline Col de Porte & 1.0 & 0.004 & 0.95 & 1460 & 0.20 & 0.7 & 950 & 0.012 \\
\hline Changri Nup & 1.0 & 0.004 & 0.95 & 1460 & 0.27 & 0.7 & 950 & 0.050 \\
\hline
\end{tabular}




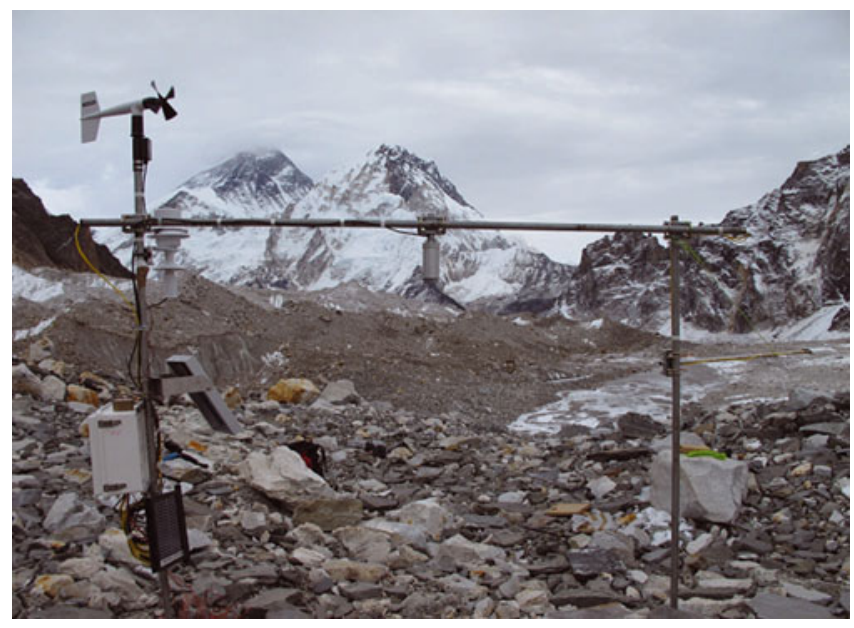

Fig. 3. Picture of the automated weather station on the debriscovered part of Changri Nup Glacier (5360 m a.s.l.) on 31 October 2010. The Everest summit is visible in the background.

The model runs were set up and initialized as follows. First, a full model run without any debris was carried out from 1 September 2010 at 00:00 to 12 April 2011 at 0:00, corresponding to the reference simulation on $\mathrm{TA}_{0}$. In order to carry out the simulation including the presence of debris, on 1 February 2011 at 12:00, i.e. on the date when artificial debris was poured on top of the snowpack, the simulated vertical profile of the physical properties of the snowpack was altered by adding the required number of debris-cover layers to simulate a 4 and a $15 \mathrm{~cm}$ thick cover. The initial temperature of all debris layers was $273.15 \mathrm{~K}$. Crocus-DEB model runs were then performed for $\mathrm{TA}_{4}$ and $\mathrm{TA}_{15}$ conditions starting on 1 February 2011 at 12:00, until 8 February 2011 at 16:00, the date of the first field measurement of the total snow depth and SWE below the artificial debris cover. The simulated profiles on 8 February at 16:00 were adjusted for $\mathrm{TA}_{4}$ and $\mathrm{TA}_{15}$, to match the observed snow depth and SWE below the artificial debris cover on each TA. Model runs for $\mathrm{TA}_{4}$ and $\mathrm{TA}_{15}$ were then initialized using the distinct starting conditions on 8 February at 16:00 and run until 12 April 2011. The same procedure was carried out when using Crocus-DEB . .

\section{Field and numerical experiments at Changri Nup Glacier}

In addition to the dedicated field experiment carried out at CDP over a temporary snow cover, a full in situ dataset obtained on Changri Nup Glacier, Nepal, was used to further evaluate Crocus-DEB. This glacier is located a few kilometres west of Khumbu Glacier (Everest area) and was equipped with an automatic weather station (AWS) on 31 October 2010, providing all the driving data needed for Crocus-DEB, i.e. half-hourly records of incoming shortwave and longwave radiation (Kipp \& Zonen CNR4 sensor), air temperature and relative humidity (artificially aspirated Vaisala HMP45C sensor), wind speed (Young 05103 sensor) and snowfall occurrence (Ultrasonic SR50 sensor). Additionally, Pt100 temperature probes, referred to as T2.5, T5, T7.5 and T10, were inserted within the $10 \mathrm{~cm}$ thick debris layer, at 2.5, 5, 7.5 and $10 \mathrm{~cm}$ below the surface, respectively. Probes were inserted to be as much as possible in contact with both clasts and air pockets, in order to be as representative as possible of the physical state of the debris.
Figure 3 provides a picture of this AWS just after its installation, showing the overall aspect of the debris layer in the vicinity. The debris particles are mainly of granite type and their size varies from $<1 \mathrm{~cm}$ to a few tens of centimetres, making a continuous heterogeneous debris cover at this elevation (5360 ma.s.I.). Below the AWS, where the temperature probes were inserted, the debris is made up of homogeneous centimetric broken gravels, roughly similar to those artificially poured at CDP. The adjustable parameters of Crocus-DEB for the Changri Nup simulation are summarized in Table 1. The main difference between this and the CDP simulation is the value of the roughness length, which is higher than at CDP, because the measurements were carried out in the presence of debris of various sizes near the measurement site, while at CDP the test areas were surrounded by snow. The simulation was initialized using $30 \mathrm{~m}$ of ice, overlaid with $10 \mathrm{~cm}$ of debris with a flat initial temperature profile of $273.15 \mathrm{~K}$ in the debris and in the ice underneath. This approach is similar to the method used successfully in previous investigations (Gerbaux and others, 2005; Lejeune, 2009; Dumont and others, 2012) using Crocus to simulate the mass balance of mountain glaciers.

\section{RESULTS - COL DE PORTE}

\section{Meteorological conditions and general overview of the field experiment}

Figure 4 provides an overview of the meteorological and snow conditions (on $\mathrm{TA}_{0}$ ) encountered at CDP from 8 February to 11 April 2011. Figure 5 shows an overview of the temperature at the top and bottom of the debris layers on $\mathrm{TA}_{4}$ and $\mathrm{TA}_{15}$, as well as the albedo and snow depth on top of the debris on $\mathrm{TA}_{15}$. The winter of 2010/11 was exceptionally dry, with little and light snowfall. From December 2010 to April 2011, cumulative precipitation was only $382 \mathrm{~kg} \mathrm{~m}^{-2}$, the lowest value recorded at CDP since 1960 (for comparison, the mean value for the period $1971-2000$ is $817 \mathrm{~kg} \mathrm{~m}^{-2}$ ). On 8 February 2011 the snow depth was only $0.28 \mathrm{~m}$ (Fig. $4 \mathrm{~d}$ ), which is only $30 \%$ of the mean value for the 1960-2010 time period at this date $(1.10 \mathrm{~m})$. The SWE of the snowpack was $140 \mathrm{~kg} \mathrm{~m}^{-2}$ (Fig. 4e). These peculiar conditions during winter 2010/11 were appropriate for carrying out our experiment. Indeed, due to the absence of snowfall between 13 January and 1 February, the snowpack was compact enough $(\rho \simeq 360$ $\mathrm{kg} \mathrm{m}^{-3}$ ) to receive gravels without being physically or thermally disturbed. Consequently, at the beginning of the experiment, the snowpack below the debris on $\mathrm{TA}_{4}$ or on $\mathrm{TA}_{15}$ can be considered physically and thermally similar to the snowpack on $\mathrm{TA}_{0}$. During the 50 days of the experiment, cumulative precipitation was only $60 \mathrm{~kg} \mathrm{~m}^{-2}$, mostly occurring during two main snowfall events (Fig. 4c), the first on 20 February between 02.00 and 16.00 UTC $\left(10 \mathrm{~kg} \mathrm{~m}^{-2}\right)$ and the second between 26 February, 19.00 UTC and 28 February, 0.00 UTC $\left(48 \mathrm{~kg} \mathrm{~m}^{-2}\right)$. After the snowfalls, the snow depth increased by a few centimetres (Fig. 4d), and concurrently the albedo of the debris-covered surface recorded a significant rise (Fig. 5c). After these snowfalls, debris was temporarily covered by snow. Such periods with snow over debris were characterized by a high albedo (Fig. 5c) and a strong attenuation with depth of the daily amplitude of the surface temperature, due to the insulating effect of snow, as observed between 20 and 25 February for 


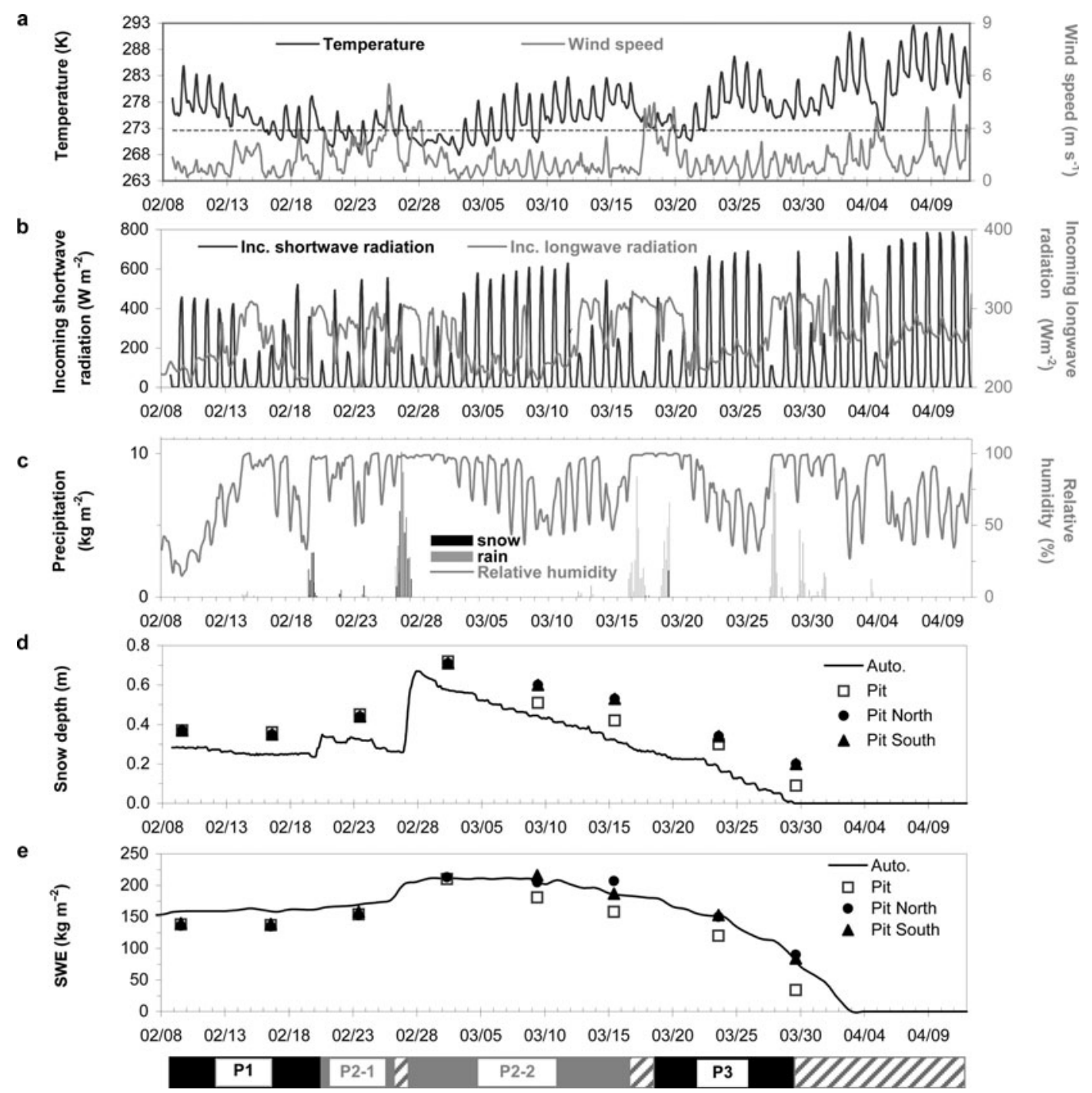

Fig. 4. In situ data collected at CDP during the field experiment in 2011. (a-c) Hourly automatic measurements of (a) air temperature and wind speed, (b) incoming shortwave and longwave radiation and (c) precipitation and relative humidity. (d, e) Weekly observations of (d) snow depth and (e) SWE on TA . Below the plots the four periods P1, P2-1, P2-2 and P3 are indicated (Table 2). The horizontal axes date format is mm/dd.

$\mathrm{TA}_{4}$ and $\mathrm{TA}_{15}$ or from 27 February to 16 March for $\mathrm{TA}_{4}$ or even 18 March for $\mathrm{TA}_{15}$ (Fig. $5 \mathrm{a}$ and $\mathrm{b}$ ).

Besides its interest for evaluating the Crocus-DEB model, this experiment provides interesting information, per se, in terms of the impact of debris on the melt rate of the underlying snow. According to the values reported by the temperature sensors placed at the bottom of the debris cover (in particular the first occurrence of a value above the melting point), the total melt below the debris occurred on 29 March (Fig. 5a) and 4 April (Fig. 5b) for $\mathrm{TA}_{4}$ and $\mathrm{TA}_{15}$, respectively. The complete melting of the snowpack was thus quicker on $\mathrm{TA}_{4}$ than on $\mathrm{TA}_{15}$, which is in line with the fact that a thicker debris layer tends to suppress melting (Østrem, 1959; Kayastha and others, 2000). The snow cover on $\mathrm{TA}_{0}$ disappeared between 29 March and 3 April, depending on the measurement chosen (e.g. automatic snow depth, manual snow depth, visual inspection) (Fig. 4d and e). This indicates that the critical thickness relevant to our experimental conditions lies between 4 and $15 \mathrm{~cm}$. However, the variability of the melt date on $\mathrm{TA}_{0}$ stresses the need for a well-defined debris-free reference against which melt rates below the debris can be compared.

Table 2. Surface state of debris-cover test areas and average meteorological conditions (air temperature, relative humidity, incoming longwave and shortwave radiation, and wind speed) during the periods P1, P2-1, P2-2 and P3 at CDP. Date format is dd/mm/yyyy

\begin{tabular}{|c|c|c|c|c|c|c|c|}
\hline \multirow[t]{2}{*}{ Period } & \multirow[t]{2}{*}{ Date } & \multirow[t]{2}{*}{ Snow on debris } & $T_{\mathrm{a}}$ & $H_{\mathrm{a}}$ & $L_{\text {in }}$ & $S_{\text {in }}$ & $u$ \\
\hline & & & $\mathrm{K}$ & $\%$ & $\mathrm{~W} \mathrm{~m}^{-2}$ & $\mathrm{~W} \mathrm{~m}^{-2}$ & $\mathrm{~ms}^{-1}$ \\
\hline P1 & 08/02/2011 17:00 to 20/02/2011 01:00 & No & 275.65 & 61 & 247 & 87 & 0.9 \\
\hline P2-1 & $20 / 02 / 201101: 00$ to $25 / 02 / 201121: 00$ & Yes & 272.45 & 87 & 272 & 91 & 1.9 \\
\hline P2-2 & $27 / 02 / 201100: 00$ to $16 / 03 / 201112: 00$ & Yes & 274.35 & 81 & 254 & 113 & 1.0 \\
\hline P3 & 18/03/2011 09:00 to 29/03/2011 08:00 & No & 276.65 & 79 & 263 & 132 & 1.1 \\
\hline
\end{tabular}




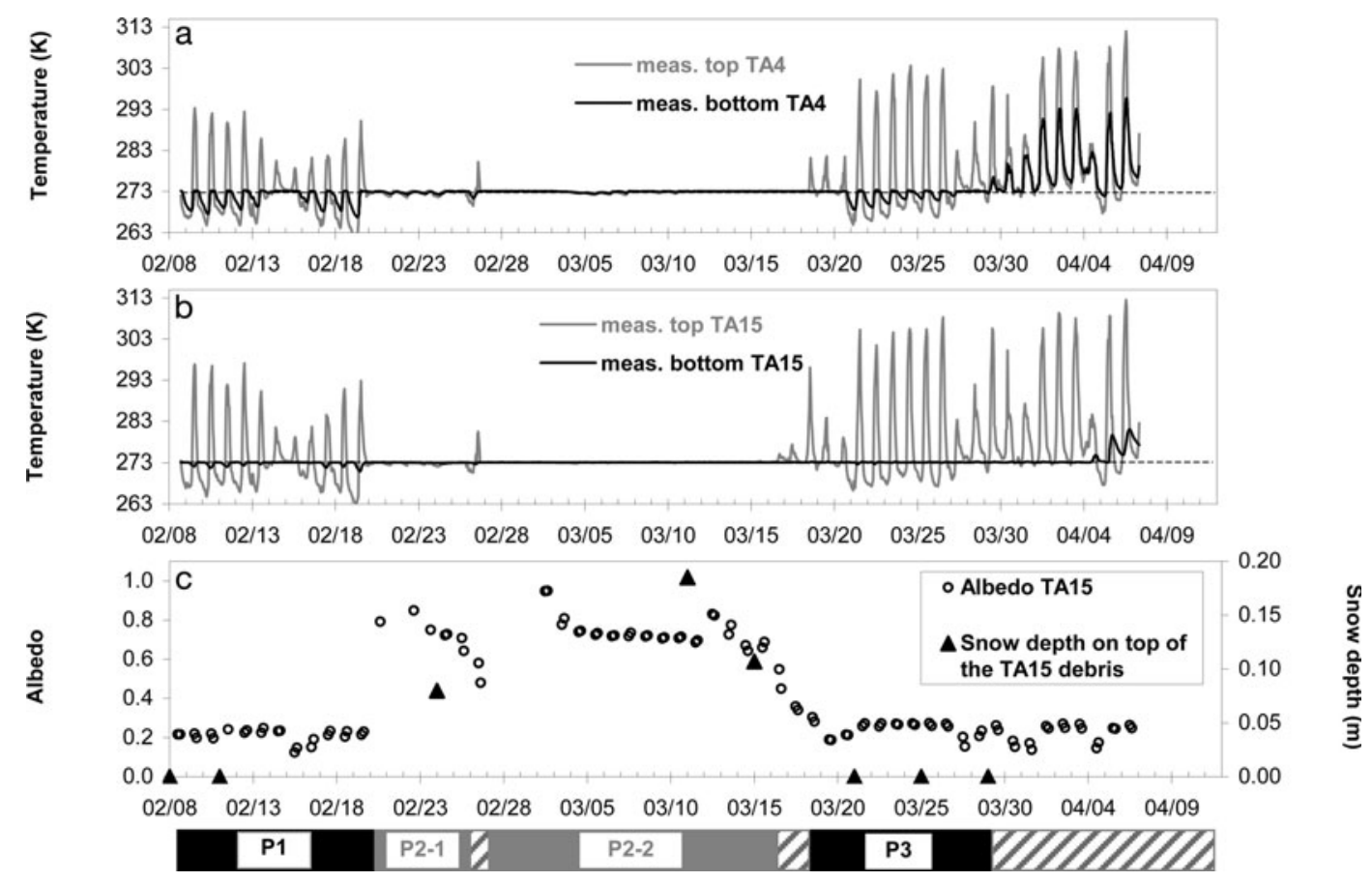

Fig. 5. Measured temperatures at the top and the bottom of the artificial (a) $4 \mathrm{~cm}\left(\mathrm{TA}_{4}\right)$ and (b) $15 \mathrm{~cm}\left(\mathrm{TA}_{15}\right)$ debris layers and (c) 3 hourly albedo measurements and observed depth of snowpack on top of the debris on $\mathrm{TA}_{15}$ debris cover. Below the plots the four periods P1, P2-1, P2-2 and P3 are indicated (Table 2). The horizontal axes date format is $\mathrm{mm} / \mathrm{dd}$.

\section{Delineation of four typical periods}

Based on the meteorological conditions and the presence or not of a transient snowpack on top of the debris, the measurement campaign was split into four periods (Figs 4-7; Table 2), and summarized along with their typical meteorological characteristics. Due to the peculiar conditions that prevailed during the 2010/11 winter, these periods were exceptionally homogeneous in terms of their meteorological conditions.

\section{Overview of the model performance throughout the experimental campaign}

For both $\mathrm{TA}_{4}$ and $\mathrm{TA}_{15}$, the performance of Crocus-DEB was analysed by comparing observed and simulated snow depth, SWE, and internal and basal temperatures of the debris, as well as heat fluxes at the bottom of the debris layers at hourly or daily timescales, until there was no snow left on the ground. Daily heat flux values at the bottom of the debris layers were cumulated over the whole experimental period, as an additional proxy for the total energy available to melt the underlying snow. Figures 6 and 7 provide an overview of these measured and simulated variables for $\mathrm{TA}_{4}$ and $\mathrm{TA}_{15}$, respectively. Below we summarize the main results of these comparisons.

\section{Snow on top of debris}

Table 3 provides measured and simulated SWE and snowdepth data above the debris on three dates during the experimental campaign, after the two significant snowfalls on 20 February and 26-27 February (Figs 4c and 5c). It shows that these two integrated snow properties are well simulated by Crocus-DEB. These snowfalls are characterized by a SWE increase visible in Figures $6 a$ and $7 a$.

\section{Total snow water equivalent}

In terms of total SWE (i.e. taking into account snow below and above the debris layers), there is overall good agreement between the model results and the observations (Figs 6a and 7a). On $\mathrm{TA}_{4}$, observed and calculated SWE agree well throughout the whole period of the experiment, except on 24 February, when the measured and simulated SWE are 145.5 and $114.7 \mathrm{~kg} \mathrm{~m}^{-2}$, respectively. The agreement is very good in March, leading to a simulated complete melting of the snow cover on 30 March that is within 1 day of the total melt date identified using temperature measurements. On $\mathrm{TA}_{15}$, in March, the melting rate is well reproduced by the model but there is systematic overestimation of the SWE (of 32,19 and $23 \mathrm{~kg} \mathrm{~m}^{-2}$ on 21, 25 and 29 March, respectively), leading to complete disappearance of the snow on 10 April, 6 days later than the field observations.

\section{Albedo}

Figure 7 a shows the observed and simulated albedo on $\mathrm{TA}_{15}$. It shows overall agreement between the two, with lower values, $\sim 0.20$, in the absence of snow, and higher values, up

Table 3. Measured and simulated values for snow depth and SWE of the transient snowpacks overlying debris cover on $\mathrm{TA}_{4}$ and $\mathrm{TA}_{15}$

\begin{tabular}{lcccc}
\hline \multirow{2}{*}{ Date } & \multicolumn{2}{c}{ SWE } & \multicolumn{2}{c}{ Snow depth } \\
& $\begin{array}{c}\text { Measured } \\
\mathrm{kg} \mathrm{m}^{-2}\end{array}$ & $\begin{array}{c}\text { Simulated } \\
\mathrm{kg} \mathrm{m}^{-2}\end{array}$ & $\mathrm{~m}$ & $\mathrm{~m}$ \\
& & & & \\
\hline $\mathrm{TA}_{4}$ & & & & \\
24 Feb 2011 & 15.0 & 12.6 & 0.08 & 0.05 \\
11 Mar 2011 & - & 50.1 & 0.21 & 0.20 \\
15 Mar 2011 & 43.3 & 44.8 & 0.14 & 0.14 \\
TA $_{15}$ & & & & \\
24 Feb 2011 & 13.9 & 13.0 & 0.08 & 0.05 \\
11 Mar 2011 & - & 48.7 & 0.19 & 0.19 \\
15 Mar 2011 & 36.8 & 43.8 & 0.11 & 0.13 \\
& & & & \\
\hline
\end{tabular}




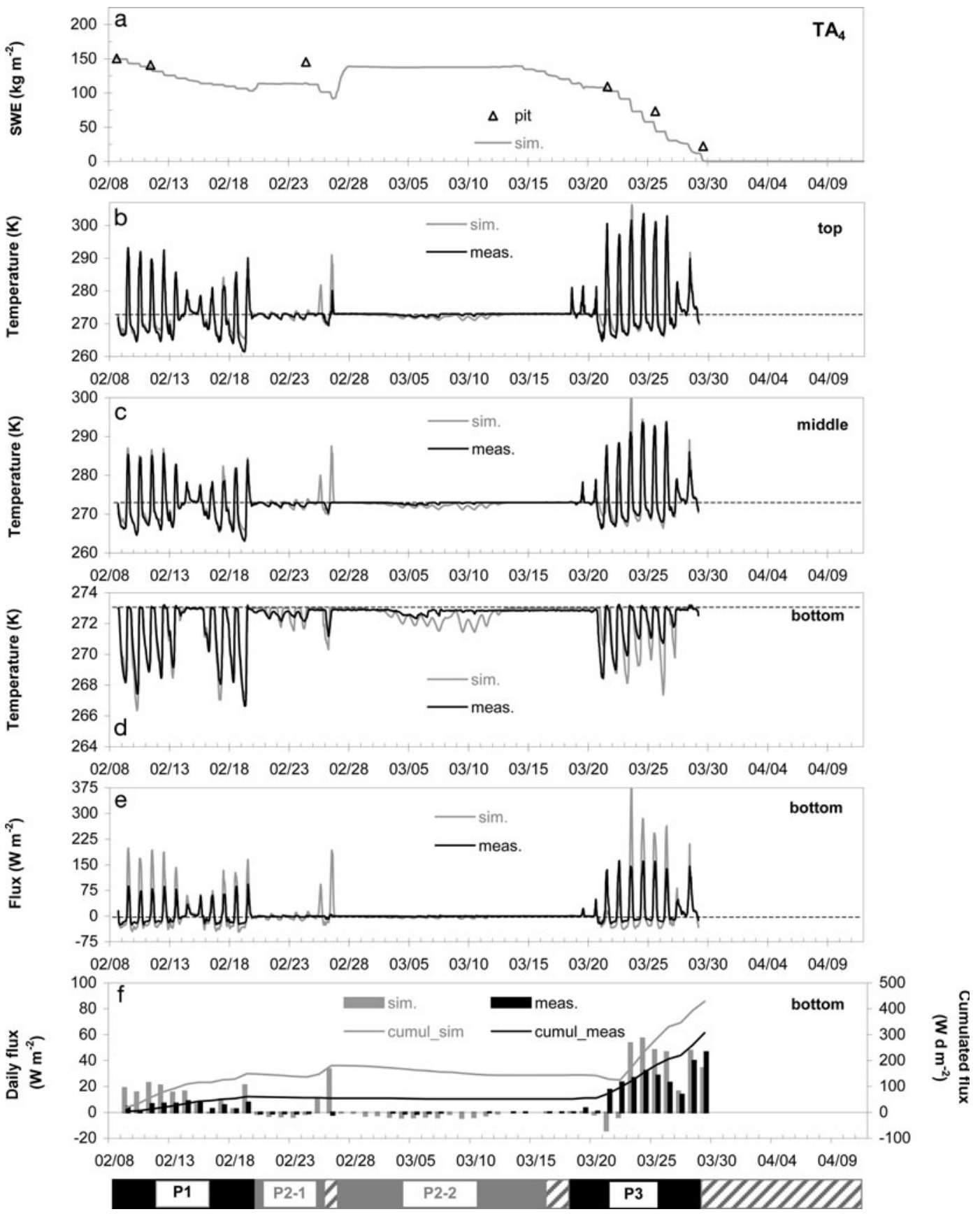

Fig. 6. (a) Simulations and occasional observations (snow coring) of total SWE in the $\mathrm{TA}_{4}$ area. (b-d) Hourly temperatures measured and simulated (b) at the top, (c) in the middle and (d) at the bottom of the debris-cover layers. For this test area $\left(\mathrm{TA}_{4}\right)$, the measurements and the simulations of $(\mathrm{e})$ the hourly heat flux at the bottom of debris layers and $(\mathrm{f})$ the daily and cumulative values of this flux are also plotted. Below the plots the four periods P1, P2-1, P2-2 and P3 are indicated (Table 2). The horizontal axes date format is mm/dd.

to 0.8 , in the presence of snow at the surface. Consistent with other evaluations of Crocus, in the presence of snow the simulated albedo is generally higher than the observations (despite the implementation of the formula reducing the snow albedo for shallow snowpacks; see above). This may explain why the complete melting of the snow on top of the debris is delayed by a few days in the simulation (cf. the observations).

\section{Heat flux and temperature within the debris}

Heat fluxes and temperatures at the top, in the middle and at the bottom of the debris-cover layers are reasonably well simulated by the model for both debris thicknesses (Figs $6 b-f$ and $7 \mathrm{~b}-\mathrm{f})$. Indeed, the model satisfactorily captures the dynamics and range of variation of the temperature and heat flux within and at the boundary of the debris cover. The main discrepancies occurred on 25 and 26 February. For these days, on both $\mathrm{TA}_{4}$ and $\mathrm{TA}_{15}$, the model overestimates the melt rate of the thin snow layer occurring on top of the debris for just a few hours (total snowfall precipitation of only $10 \mathrm{~kg} \mathrm{~m}^{-2}$ ), explaining why temperatures and heat fluxes then show a large daily variability, in contrast to the observations. Consequently, the calculated melting during these two days is 20 and $10 \mathrm{~kg} \mathrm{~m}^{-2}$ over $\mathrm{TA}_{4}$ and $\mathrm{TA}_{15}$, respectively, although it was insignificant from the measurements. Between 2 and 13 March, simulated temperatures were below the melting point, leading to slightly negative daily basal fluxes, although the debris always remained at or 


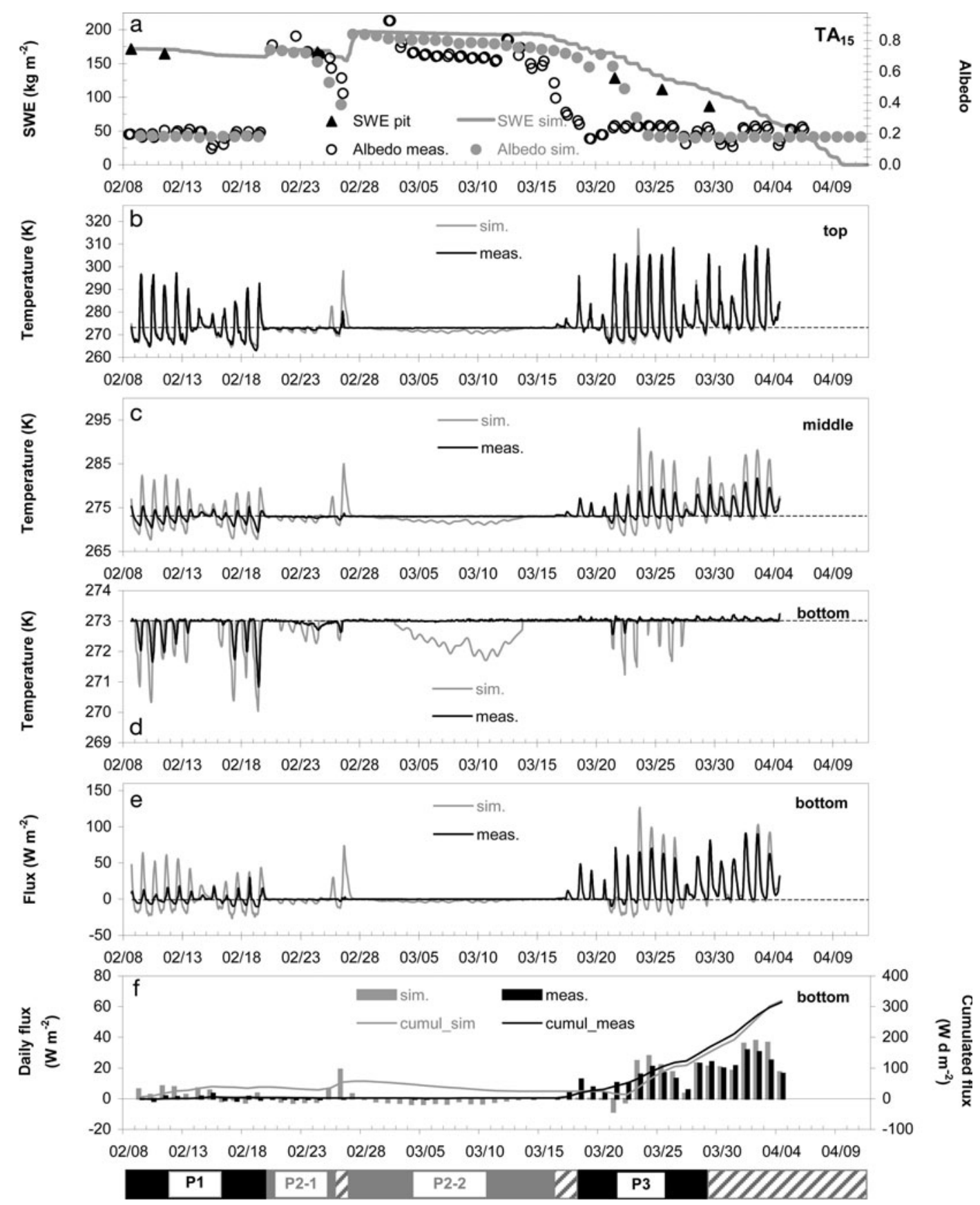

Fig. 7. (a) Hourly simulations and occasional observations (snow coring) of total SWE, and observed and simulated albedo in the TA 15 area. (b-d) Hourly temperatures measured and simulated (b) at the top, (c) in the middle and (d) at the bottom of the debris-cover layers. For this test area $\left(\mathrm{TA}_{4}\right)$, the measurements and the simulations of (e) the hourly heat flux at the bottom of debris layers and (f) the daily and cumulative values of this flux are also plotted. Below the plots, the four periods P1, P2-1, P2-2 and P3 are indicated (Table 2). The horizontal axes date format is $\mathrm{mm} / \mathrm{dd}$.

slightly below freezing. Consequently, the model erroneously simulated a cooling of the snow below the debris during period P2-2. Finally, the relative differences of the observed and calculated diurnal amplitudes of the debris temperatures and basal fluxes are higher over $\mathrm{TA}_{15}$ than over $\mathrm{TA}_{4}$ during period $\mathrm{P} 1$. This is also the case during period $\mathrm{P} 3$, but exclusively for debris temperatures and not for heat flux. Indeed, between 20 and 27 March anomalously low temperatures were simulated at the bottom of the debris over $\mathrm{TA}_{15}$, albeit daily basal heat fluxes were well simulated. Although the date of the complete disappearance of the snow is well simulated over $\mathrm{TA}_{4}$, the calculated cumulative heat flux on 29 March is $120 \mathrm{~W} \mathrm{~d} \mathrm{~m}^{-2}$ higher than the observed cumulative flux, i.e. a discrepancy of $\sim 20 \%$. In contrast, over $\mathrm{TA}_{15}$, the simulated and measured cumulative fluxes are in good agreement, but the date of snow disappearance is simulated to be too late. These discrepancies clearly show that there are cases of error compensation in the model.

\section{Mean diurnal cycle of thermal conditions during periods of homogeneous meteorological conditions}

To follow the thermal evolution of the debris layers during the day, the mean diurnal cycle of the observed and simulated temperatures at the top, in the middle and at the bottom of the debris layer were calculated, as well as the 

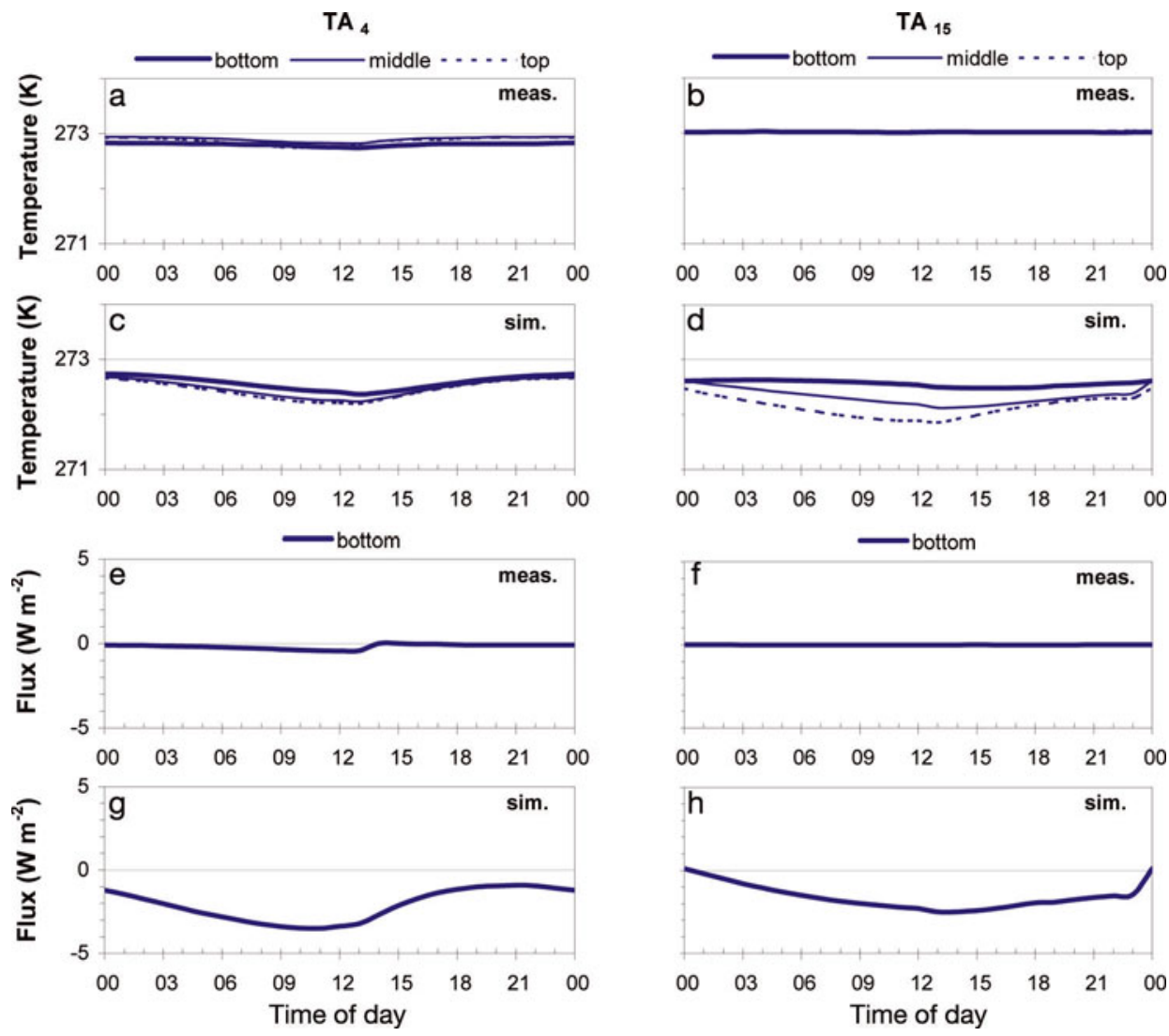

Fig. 8. Diurnal cycle of temperatures ( $(a, b)$ measured; $(c, d)$ simulated) at the base, in the middle and at the top of the debris-cover layers, and bottom fluxes ( $(\mathrm{e}, \mathrm{f})$ measured; $\left(\mathrm{g}\right.$, h) simulated) on the artificial 4 and $15 \mathrm{~cm}$ debris layers $\left(\mathrm{TA}_{4}\right.$ and $\mathrm{TA}_{15}$, respectively) during period $\mathrm{P} 2-2$.

heat fluxes at the bottom of the debris for every period given in Table 2. Since diurnal cycles are very similar between periods P1 and P3 (no snow on debris) and between periods P2-1 and P2-2 (debris covered by snow), only the mean diurnal cycles of periods P2-2 (17.5 days) and P3 (11 days) are reported in Figures 8 and 9, respectively. Table 4 summarizes the statistics of temperatures and fluxes observed and calculated on both debris-covered test areas during the four periods considered.

\section{Snow covering the debris (period P2-2)}

During period $\mathrm{P} 2-2$, i.e. when snow was covering debris on $\mathrm{TA}_{4}$ and $\mathrm{TA}_{15}$, field data confirm that the presence of snow had a particularly strong attenuating effect on heat transfer, as seen in Figure 8, where the snow layer was $10-30 \mathrm{~cm}$ thick. At $\mathrm{TA}_{4}$ (Fig. 8a), temperatures at the three measurement levels (top, middle and bottom) always remain slightly below the melting point. $T_{\text {bottom-4-meas }}$ ranged between 272.9 and $273.0 \mathrm{~K}$ with a daily mean of $273.0 \mathrm{~K}$. Daily means of $T_{\text {mid-4-meas }}$ and $T_{\text {top-4-meas }}$ were 273.1 and $273.0 \mathrm{~K}$, respectively, and their respective daily amplitudes of 0.1 and $0.2 \mathrm{~K}$ were barely higher than that of $T_{\text {bottom-4-meas. At }} \mathrm{TA}_{15}$, debris always remained at the melting temperature (Fig. 8b) and the basal flux, Qc-bottom-15-meas, was 0 (Fig. 8f). At $\mathrm{TA}_{4}$ the daily basal flux was only $-0.2 \mathrm{~W} \mathrm{~m}^{-2}$ (Fig. 8e).

The results of the simulation during period P2-2 are given in Figure 8c, d, g and h. They show that the numerical simulations overestimate the diurnal amplitude of debris temperature. At both $\mathrm{TA}_{4}$ and $\mathrm{TA}_{15}$, simulated temperatures are always below the melting point, and minimal at midday. Temperature increases from the top of the debris layer toward the bottom. Although measured basal fluxes were always 0 , or very close to 0 , simulated fluxes are always negative and range between -1 and $-3.5 \mathrm{~W} \mathrm{~m}^{-2}$ at $\mathrm{TA}_{4}$ and between 0 and $-2.5 \mathrm{Wm}^{-2}$ at $\mathrm{TA}_{15}$. The model tends to simulate the downward propagation of a 'cold wave', although measurements indicate that the snow below the debris is almost perfectly insulated from the surface.

\section{Melting period without snow on top of the debris (period P3)}

During period P3, corresponding to the main melt period without snow on top of the debris, experimental results (Fig. 9a and b) indicate that the surface temperatures measured on the debris over both test areas ( $T_{\text {top-4-meas }}$ and $\left.T_{\text {top-15-meas }}\right)$ minimize and maximize at the same time of the day, at around 5.00 and 13.00 UTC. The diurnal amplitude of $T_{\text {top-4-meas }}$ is $22 \mathrm{~K}$, slightly lower than that of $T_{\text {top-15-meas }}(26 \mathrm{~K})$. At the surface, the debris follows a thermal cycle, which appears to be similar regardless of the debris thickness, even if the maximum temperature is $5 \mathrm{~K}$ higher over $\mathrm{TA}_{15}$ than over $\mathrm{TA}_{4}$. In the middle of the debris layer, the diurnal amplitude of the temperature measured at $-2 \mathrm{~cm}$ on $\mathrm{TA}_{4}\left(T_{\text {mid }-4-\text { meas }}\right)$ is $15 \mathrm{~K}$, three times higher than at $-7.5 \mathrm{~cm}$ on $\mathrm{TA}_{15}\left(T_{\text {mid-15-meas }}\right)$ (Fig. 9a and b). Also visible is a clear delay for $T_{\text {mid-15-meas }}$ compared to $T_{\text {mid-4-meas, }}$ the minimum and maximum of $T_{\text {mid-15-meas }}$ being reached at 9.00 and 16.00 UTC, respectively, $\sim 4$ and 3 hours after $T_{\text {mid-4-meas, }}$ respectively. The heat flux propagating within the debris is then all the more attenuated and delayed as the debris is deeper in the layer. At the bottom of the debris layer, sensors were installed at the snow/debris interface, preventing the temperature from exceeding the 

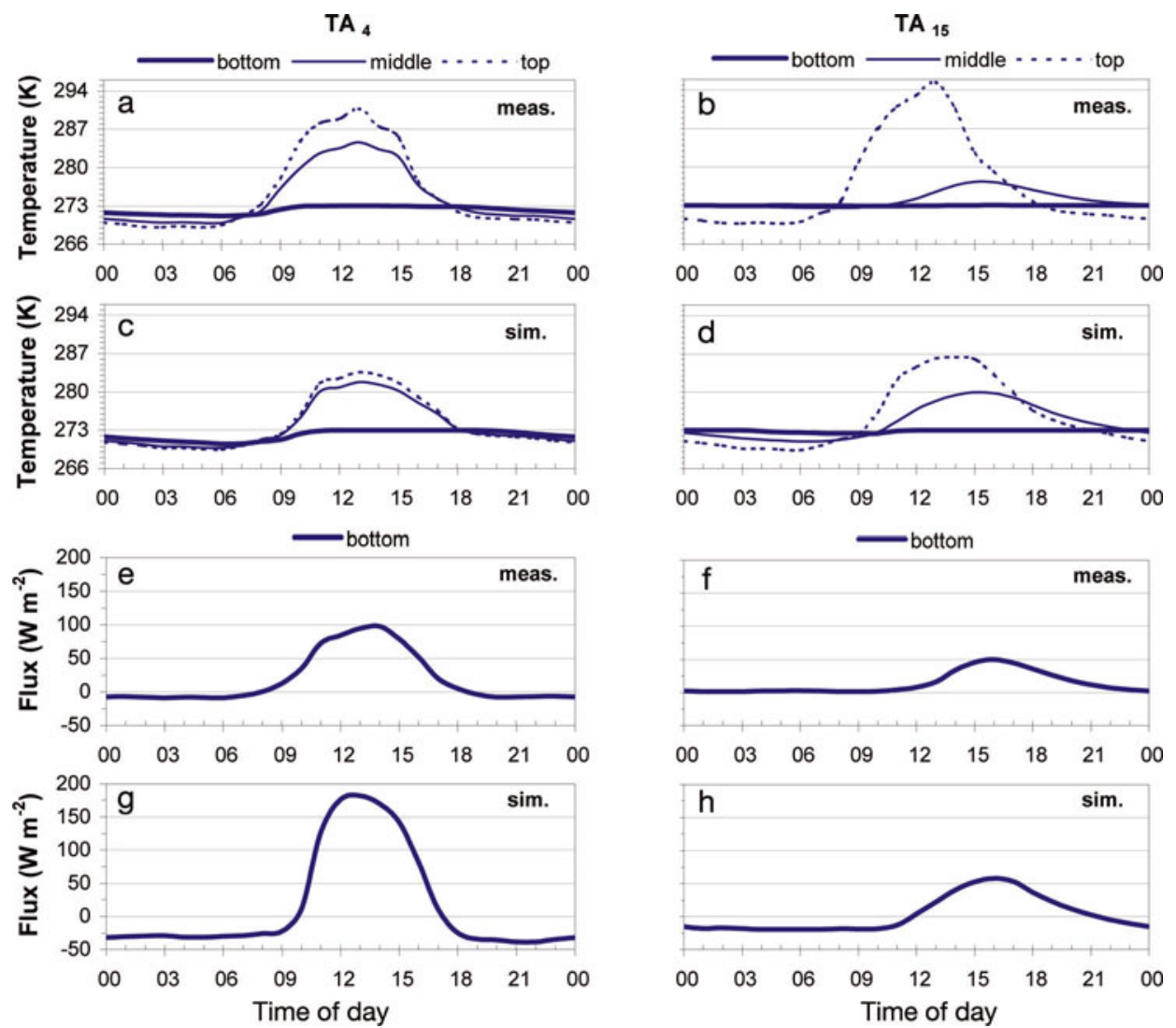

Fig. 9. Same as Figure 8 , but during period $\mathrm{P} 3$. Note the top of both layers is $0 \mathrm{~cm}$, the middle is $-2 \mathrm{~cm}$ for $\mathrm{TA}_{4}$ and $-7.5 \mathrm{~cm}$ for $\mathrm{TA}_{15}$, and the bottom $-4 \mathrm{~cm}$ for $\mathrm{TA}_{4}$ and $-15 \mathrm{~cm}$ for $\mathrm{TA}_{15}$.

melting point. At the bottom of $\mathrm{TA}_{15}$, the temperature,

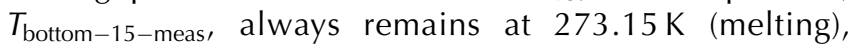
although on $\mathrm{TA}_{4}$, underlying snow melts for only 6 hours a day, between 10.00 and 16.00 UTC. The rest of the time,
$T_{\text {bottom-4-meas }}$ is below the melting point, reaching its minimum value at 6.00 UTC $(271.3 \mathrm{~K})$. The underlying snow thus alternates between thawing and refreezing along the diurnal cycle.

Table 4. Statistics of diurnal cycles of temperatures (at the bottom, in the middle and at the top of the debris layers) and fluxes (at the bottom of the debris layers) measured and simulated during the four periods P1, P2-1, P2-2 and P3 on $\mathrm{TA}_{4}$ and $\mathrm{TA}_{15}$. rms refers to the root-meansquare error of the measured and simulated time series

\begin{tabular}{|c|c|c|c|c|c|c|c|c|c|}
\hline & & \multicolumn{4}{|c|}{$\mathrm{TA}_{4}$} & \multicolumn{4}{|c|}{$\mathrm{TA}_{15}$} \\
\hline & & $Q_{\mathrm{c}-\text { bottom }}$ & $T_{\text {bottom }}$ & $T_{\text {mid }}$ & $T_{\text {top }}$ & $Q_{\mathrm{c}-\text { bottom }}$ & $T_{\text {bottom }}$ & $T_{\text {mid }}$ & $T_{\text {top }}$ \\
\hline & & $\mathrm{Wm}^{-2}$ & K & K & K & $W m^{-2}$ & K & K & K \\
\hline & Measured average & 5.4 & 271.5 & 272.1 & 272.7 & 0.5 & 272.9 & 273.0 & 273.7 \\
\hline & Simulated average & 13.3 & 271.5 & 272.7 & 272.9 & 3.4 & 272.7 & 273.3 & 273.6 \\
\hline \multirow[t]{5}{*}{ Period P1 } & Mean deviation & 7.9 & 0.0 & 0.6 & 0.2 & 2.8 & -0.3 & 0.3 & -0.1 \\
\hline & $\mathrm{rms}$ & 29.9 & 0.3 & 0.9 & 1.2 & 16.0 & 0.5 & 2.6 & 2.0 \\
\hline & $r^{2}$ & 0.92 & 0.95 & 0.98 & 0.98 & 0.63 & 0.26 & 0.50 & 0.91 \\
\hline & Measured average & -0.8 & 272.8 & 272.8 & 272.7 & -0.3 & 273.1 & 273.0 & 273.0 \\
\hline & Simulated average & 0.1 & 272.9 & 273.0 & 273.0 & -0.5 & 273.0 & 273.0 & 273.0 \\
\hline \multirow[t]{5}{*}{ Period P2-1 } & Mean deviation & 0.9 & 0.1 & 0.2 & 0.3 & -0.3 & -0.1 & -0.1 & 0.0 \\
\hline & $\mathrm{rms}$ & 8.4 & 0.2 & 0.6 & 0.7 & 3.0 & 0.1 & 0.5 & 0.9 \\
\hline & $r^{2}$ & 0.81 & 0.73 & 0.74 & 0.75 & 0.52 & 0.00 & 0.18 & 0.77 \\
\hline & Measured average & -0.2 & 273.0 & 273.1 & 273.0 & 0.0 & 273.2 & 273.2 & 273.2 \\
\hline & Simulated average & -2.1 & 272.7 & 272.6 & 272.6 & -1.6 & 272.7 & 272.5 & 272.3 \\
\hline \multirow[t]{5}{*}{ Period P2-2 } & Mean deviation & -2.0 & -0.2 & -0.4 & -0.4 & -1.6 & -0.5 & -0.7 & -0.9 \\
\hline & $\mathrm{rms}$ & 2.1 & 0.3 & 0.4 & 0.4 & 1.8 & 0.5 & 0.7 & 0.9 \\
\hline & $r^{2}$ & 0.65 & 0.84 & 0.91 & 0.81 & 0.20 & 0.24 & 0.47 & 0.30 \\
\hline & Measured average & 19.2 & 272.4 & 274.6 & 275.6 & 13.5 & 273.2 & 274.3 & 277.0 \\
\hline & Simulated average & 17.0 & 272.2 & 274.0 & 274.3 & 3.1 & 273.0 & 274.6 & 275.6 \\
\hline \multirow[t]{3}{*}{ Period P3 } & Mean deviation & -2.1 & -0.2 & -0.6 & -1.3 & -10.4 & -0.2 & 0.3 & -1.3 \\
\hline & $\mathrm{rms}$ & 41.4 & 0.4 & 1.8 & 3.6 & 15.2 & 0.2 & 1.6 & 4.6 \\
\hline & $r^{2}$ & 0.97 & 0.88 & 0.92 & 0.89 & 0.97 & 0.41 & 0.95 & 0.74 \\
\hline
\end{tabular}


The measured conductive heat fluxes at the snow/debris interface on $\mathrm{TA}_{4}$ and $\mathrm{TA}_{15}, Q_{\mathrm{c}-\text { bottom-4-meas }}$ and $Q_{\text {c-bottom-15-meas, }}$ respectively, are plotted in Figure 9e and f. On $\mathrm{TA}_{4}, Q_{\mathrm{c}-\text { bottom-4-meas }}$ is positive during daytime between 8:00 and 18:00, with a maximum value at 14:00 $\left(100 \mathrm{~W} \mathrm{~m}^{-2}\right)$, and remains slightly negative $\left(\sim-7 \mathrm{~W} \mathrm{~m}^{-2}\right)$ the rest of the time. On $\mathrm{TA}_{15}, Q_{\mathrm{c}-\text { bottom-15-meas }}$ always remains positive, with significant values only between 10:00 and 24:00, a maximum of $50 \mathrm{~W} \mathrm{~m}^{-2}$ being reached at around 16:00. Even if $Q_{\text {c-bottom-4-meas }}$ is negative at night, which means that refreezing occurs under $\mathrm{TA}_{4}$ debris, its daily mean is $19 \mathrm{~W} \mathrm{~m}^{-2}$ (cf. $14 \mathrm{~W} \mathrm{~m}^{-2}$ for $Q_{\mathrm{c}-\text { bottom-15-meas }}$ ), indicating that daily melting is higher below $\mathrm{TA}_{4}$ than below $\mathrm{TA}_{15}$.

Figure $9 c, d, g$ and $h$ show the results of the simulations. Comparison of Figure 9a and c for $\mathrm{TA}_{4}$, or Figure $9 \mathrm{~b}$ and $\mathrm{d}$ for $\mathrm{TA}_{15}$, shows that simulated temperatures agree fairly well with observations, as also confirmed by correlation coefficients in Table 4 ( $r^{2}$ values $0.74-0.95$, except for temperature at the bottom of $\mathrm{TA}_{15}$ where $r^{2}$ values are only 0.41 but the temperature variations are small). Nevertheless, the model fails to consistently reproduce the maximal heating at the surface of $\mathrm{TA}_{4}$ and $\mathrm{TA}_{15}$, with underestimations as high as 7 and $9 \mathrm{~K}$, respectively. At the surface and in the middle of $\mathrm{TA}_{4}$, mean daily values of $T_{\text {top-4-sim }}$ and $T_{\text {mid-4-sim }}$ are 1.3 and $0.6 \mathrm{~K}$, respectively, lower than the measurements (Table 4). At $\mathrm{TA}_{15}$, daily $T_{\text {top- }-15-\text { sim }}$ is $1.3 \mathrm{~K}$ lower than $T_{\text {top-15-meas }}$ but daily $T_{\text {mid-15-sim }}$ is $0.3 \mathrm{~K}$ higher than $T_{\text {mid-15-meas }}$. The diurnal amplitude of $T_{\text {mid-4-sim }}$ is also weaker than that of $T_{\text {mid-4-meas }}$ (Fig. 9a and c), although that of $T_{\text {mid-15-sim }}$ is higher than that of $T_{\text {mid-15-meas }}$ (Fig $9 \mathrm{~b}$ and d). Finally, at the bottom of both debris layers, daily mean simulated temperatures, $T_{\text {bottom-4-sim }}$ and $T_{\text {bottom-15-sim, }}$ are slightly lower $(\sim 0.2 \mathrm{~K})$ than observations. There is good agreement between $T_{\text {bottom-4-sim }}$ and $T_{\text {bottom-4-meas }}$ with observed and simulated melting conditions encountered between 10.00 and 16.00 UTC, but $T_{\text {bottom-15-sim remains }}$ slightly below the melting point between 4.00 and 12.00 UTC, although observations show that underlying snow is still melting.

The comparisons between Figure $9 \mathrm{e}$ and $\mathrm{g}$ and between Figure $9 \mathrm{f}$ and $\mathrm{h}$ show that the model is able to consistently reproduce the timing of the daily cycle of the heat flux at the bottom of $\mathrm{TA}_{4}$ or $\mathrm{TA}_{15}$ (with $r^{2}$ between simulated and measured fluxes as high as 0.97 and 0.88 , respectively; Table 4), but fails to properly simulate its daily amplitude. Indeed, the daily amplitude of $Q_{\mathrm{c}-\text { bottom-4-sim }}\left(220 \mathrm{~W} \mathrm{~m}^{-2}\right)$

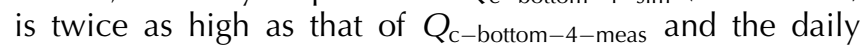
amplitude of $Q_{\mathrm{c}-\text { bottom-15-sim }}\left(75 \mathrm{~W} \mathrm{~m}^{-2}\right)$ is one-third higher

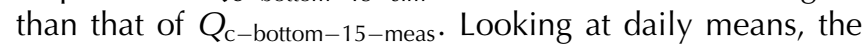
agreement is much better, with daily values of $Q_{\text {c-bottom-4-sim }}$ and $Q_{\text {c-bottom-4-meas }}$ equal to 17 and $19 \mathrm{~W}$ $\mathrm{m}^{-2}$, respectively, and daily values of $Q_{\mathrm{c}-\text { bottom-15-sim }}$ and

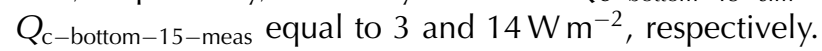

\section{Impact of assumptions about under-debris temperature}

Model runs using the reference version of Crocus-DEB and the modified version setting the temperature of the snow below the debris to the melting point (Crocus-DEB $\mathrm{m}_{\mathrm{m}}$ ) were compared in terms of net heat flux at the debris/belowdebris interface, also considering the additional (artificial) amount of energy used to raise the temperature below the debris to the melt temperature. The latter was converted to a flux, allowing comparison with the net interface flux, although, strictly speaking, it does not correspond to a flux through an interface, because in Crocus-DEB $\mathrm{m}_{\mathrm{m}}$ energy may be artificially added to any layer below the debris. (Note that as the Changri Nup Glacier simulation does not correspond to the melt season, it is unreasonable to compare CrocusDEB model runs with Crocus-DEB $B_{m}$ there.) At CDP, total melt simulated by Crocus-DEB $\mathrm{m}_{\mathrm{m}}$ occurred 5.7 and 4.3 days before the standard Crocus-DEB simulation at $\mathrm{TA}_{4}$ and $\mathrm{TA}_{15}$, respectively. Table 5 shows the results in terms of heat flux at the debris/underlying-snow interface and basal runoff, respectively, at CDP. During periods $\mathrm{P} 2-1$ and $\mathrm{P} 2-2$, i.e. in the presence of snow on top of the debris, heat fluxes at the debris/underlying-snow interface are negligible $\left(<1 \mathrm{~W} \mathrm{~m}^{-2}\right)$ for both models, although the energy added to the underlying snow corresponds to $2 \mathrm{~W} \mathrm{~m}^{-2}$ or more. During the cold, dry period $\mathrm{P} 1$, discrepancies are higher between the two versions of the model and between $\mathrm{TA}_{4}$ and $\mathrm{TA}_{15}$. Using Crocus-DEB $\mathrm{B}_{\mathrm{m}}$ decreases the net heat flux through the debris (as much as halving it in the case of $\mathrm{TA}_{4}$ ), while the additional equivalent heat flux is of the order of twice the heat flux through the debris simulated by Crocus-DEB. However, it should be noted that this period does not correspond to a melt period, so we anticipate that meltperiod debris-cover models will not be used under such conditions. During the main melt season (P3), the heat flux at the bottom of the debris on $\mathrm{TA}_{4}$ using Crocus-DEB $\mathrm{m}$ is less than half that of Crocus-DEB, although Crocus-DEB $B_{m}$ leads to a total melt occurring several days earlier than CrocusDEB. Using Crocus-DEB $\mathrm{m}_{\mathrm{m}}$ thus leads to overestimation of the melt rate below the debris, even if this cannot be concluded when looking only at the net heat flux through the interface below the debris. The heat flux at the bottom of the debris on $\mathrm{TA}_{15}$ is rather similar in the case of Crocus-DEB $\mathrm{m}$ and Crocus-DEB, consistent with the fact that the temperature at the base of a thicker debris cover exhibits less variation and, in particular during the melt period, the melt operates more continuously (Figs 6 and 7). Over the full measurement period, the same situation as during P3 is found, consistent with the fact that this period is the longest and also that much of the net flux through the debris occurs during the melt period. In terms of basal runoff, the use of Crocus$\mathrm{DEB}_{\mathrm{m}}$ leads to a simulated basal runoff, which is directly related to the melt flux (but accounts for the impact of rain), that is $\sim 10 \%$ higher during the melt period than the results of Crocus-DEB. During periods not dominated by melt, the discrepancy is even higher, probably because, in addition to increasing the melting below the debris, Crocus-DEB $\mathrm{m}_{\mathrm{m}}$ does not allow any meltwater to refreeze within the debris layers. When liqud water is present in the ice/snow layer located just above the debris layers, it is instantaneously drained through the debris to the ice/snow layer just below the debris layers. Note that period P1, which was not simulated to be a melt period using Crocus-DEB, owing to cold and dry meteorological conditions in February, becomes a period with significant melt using Crocus-DEB $\mathrm{m}_{\mathrm{m}}$, with on average $8 \mathrm{~kg} \mathrm{~m}^{-2} \mathrm{~d}^{-1}$ runoff flux below $\mathrm{TA}_{4}$.

\section{RESULTS - CHANGRI NUP}

\section{Meteorological conditions}

An overview of the meteorological conditions between 16 November and 31 December 2010 at Changri Nup Glacier is given in Figure 10. This shows that during this 


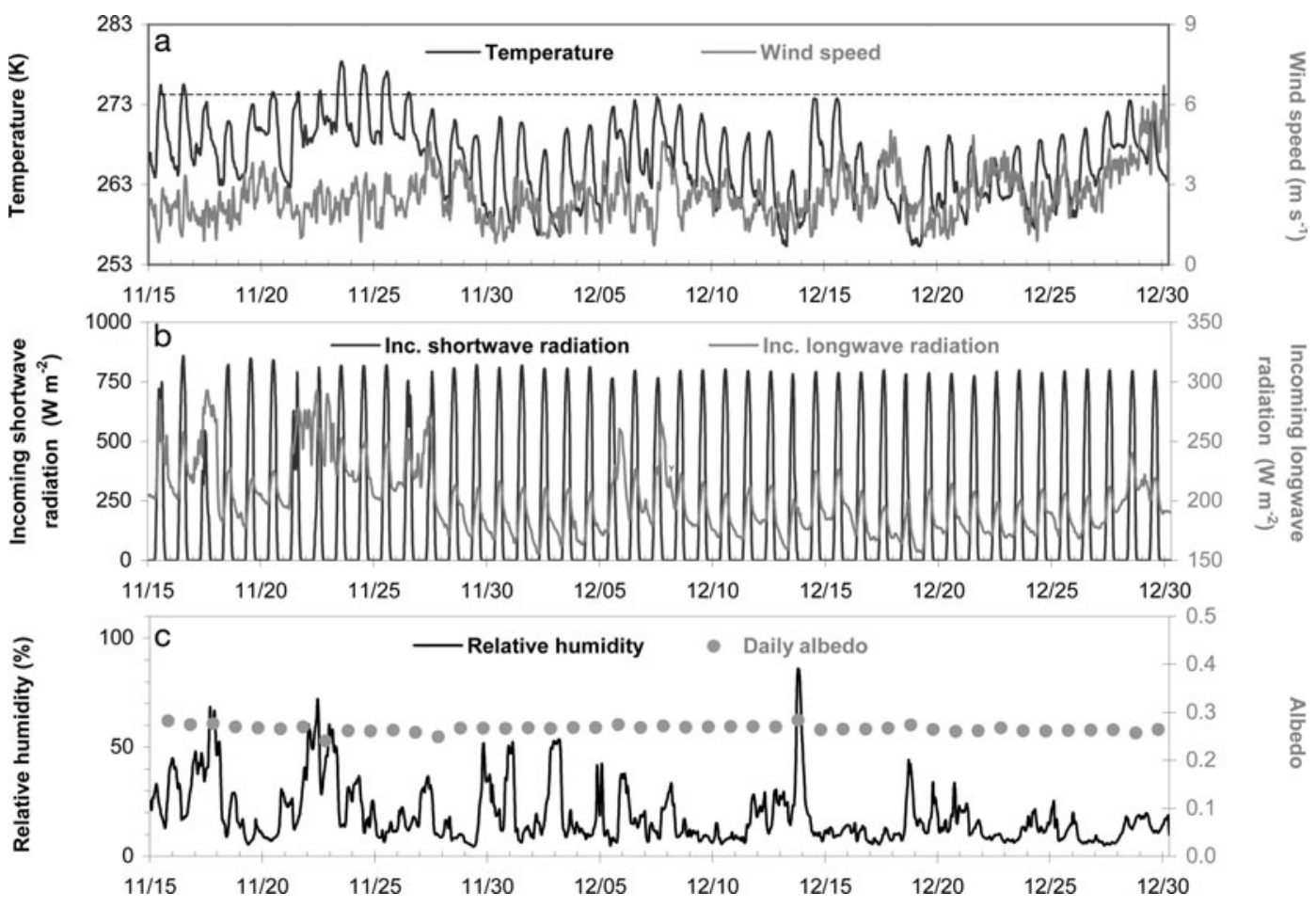

Fig. 10. In situ data collected at Changri Nup Glacier in 2010. (a) Air temperature and wind speed. (b) Incoming shortwave and longwave radiation. (c) Relative humidity and daily albedo. The horizontal axes date format is $\mathrm{mm} / \mathrm{dd}$.

period the glacier was exposed to typical winter dry conditions prevailing in this part of the Himalaya (Bookhagen and Burbank, 2010), i.e. no precipitation, almost no clouds, moderate wind speed $\left(2.6 \mathrm{~m} \mathrm{~s}^{-1}\right)$, low air temperature $(265.95 \mathrm{~K})$ and humidity $(19.1 \%)$, high incoming solar radiation $\left(194 \mathrm{~W} \mathrm{~m}^{-2}\right)$ and low incoming longwave radiation $\left(201 \mathrm{~W} \mathrm{~m}^{-2}\right)$. This period was selected because the specific and extremely homogeneous conditions encountered make it challenging for the model to reproduce the thermal behaviour of the debris layer as well as the ice/ debris interface. Indeed, there was no snow cover over the debris (albedo $=0.27$ ), favouring the absorption of solar radiation by the debris surface during daytime, and causing much energy loss during the night through outgoing longwave radiation. Consequently, energy exchanges across the ice/debris/atmosphere continuum are high and very variable over a day, as evidenced by the large daily amplitude of air temperature (sometimes >15 K; Fig. 10).

Table 5. Impact of setting below-debris temperature to the melt temperature at CDP during the designated periods. 'Interface flux' corresponds to the net heat flux at the debris/underlying-snow interface, while 'Additional flux' refers to the amount of energy artificially added to the underlying snow layers to raise their temperature to the melt temperature. Periods P3 and Full are not the same for $\mathrm{TA}_{4}$ and $\mathrm{TA}_{15}$, because the total melt date is different for the two situations (the end date of P3 corresponds here to the complete melt date of the simulation keeping below-debris temperature at the melt temperature). The table also gives the simulated cumulative runoff at the base of the snowpack using Crocus-DEB and the relative change induced by the use of Crocus-DEB $\mathrm{m}_{\mathrm{m}}$. Date format is $\mathrm{dd} / \mathrm{mm} / \mathrm{yyyy}$

\begin{tabular}{|c|c|c|c|c|c|}
\hline & & \multicolumn{2}{|c|}{ Interface flux } & \multirow{3}{*}{$\begin{array}{l}\text { Additional flux } \\
\text { Modelled } \\
\mathrm{W} \mathrm{m}^{-2}\end{array}$} & \multirow{3}{*}{$\begin{array}{c}\text { Cumulative melt flux } \\
\text { Reference } \\
\mathrm{kg} \mathrm{m}^{-2}\end{array}$} \\
\hline & & Reference & Modelled & & \\
\hline & & $\mathrm{W} \mathrm{m}^{-2}$ & $\mathrm{~W} \mathrm{~m}^{-2}$ & & \\
\hline \multicolumn{6}{|l|}{$\mathrm{TA}_{4}$} \\
\hline $\mathrm{P} 1$ & 08/02/2011 $17: 00$ to $20 / 02 / 201101: 00$ & 12.4 & 6.7 & 20.6 & $48(+92 \%)$ \\
\hline P2-1 & $20 / 02 / 201101: 00$ to $25 / 02 / 201121: 00$ & 0.2 & 0.1 & 4.2 & $15(+44 \%)$ \\
\hline P2-2 & $27 / 02 / 201100: 00$ to $16 / 03 / 201112: 00$ & -2.1 & -2.4 & 1.8 & $14(+39 \%)$ \\
\hline P3 & $18 / 03 / 201109: 00$ to $24 / 03 / 201113: 00$ & 9.8 & 3.6 & 11.3 & $76(+12 \%)$ \\
\hline Full & 08/02/2011 17:00 to $24 / 03 / 201113: 00$ & 4.5 & 1.9 & 8.5 & $204(+33 \%)$ \\
\hline \multicolumn{6}{|l|}{$\mathrm{TA}_{15}$} \\
\hline $\mathrm{P} 1$ & 08/02/2011 $17: 00$ to $20 / 02 / 201101: 00$ & 3.6 & 2.6 & 8.4 & $13(+181 \%)$ \\
\hline P2-1 & $20 / 02 / 201101: 00$ to $25 / 02 / 201121: 00$ & -0.5 & -0.6 & 2.1 & $13(+32 \%)$ \\
\hline P2-2 & $27 / 02 / 201100: 00$ to $16 / 03 / 201112: 00$ & -1.6 & -1.9 & 2.2 & $16(+52 \%)$ \\
\hline Full & 08/02/2011 $17: 00$ to $05 / 04 / 201123: 00$ & 6.2 & 5.7 & 3.7 & $284(+18 \%)$ \\
\hline
\end{tabular}




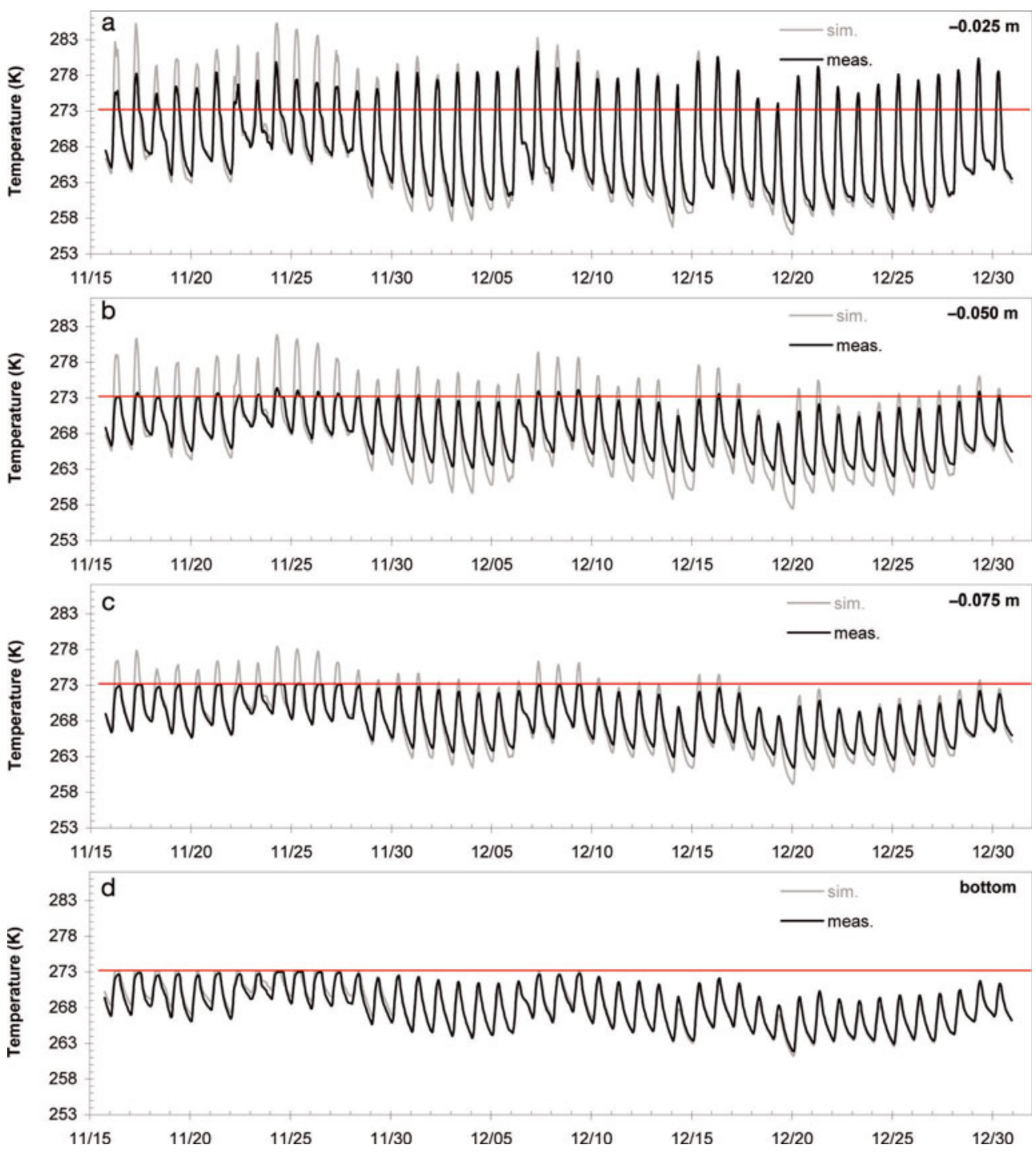

Fig. 11. Measured and simulated internal debris-cover temperatures at Changri Nup Glacier at depths of (a) 2.5 , (b) 5.0 , (c) 7.5 and (d) $10 \mathrm{~cm}$ (the ice/debris interface) within the natural $10 \mathrm{~cm}$ thick debris layer. The horizontal axes date format is $\mathrm{mm} / \mathrm{dd}$.

\section{Mean diurnal cycle of heat transfer within the natural debris layers}

Figure 11 shows the hourly evolution of measured and calculated temperatures of the debris over the entire study. As seen before, the model yields good results for simulating the thermal evolution of the debris, especially near the surface (at $-2.5 \mathrm{~cm}$ ) and at the ice/debris interface (at $-10 \mathrm{~cm}$ ). To study the ability of the model to simulate the day-to-day variability of the debris temperatures, we selected two contrasting days: the warmest of the period (25 November 2010; daily mean air temperature $272.75 \mathrm{~K}$ ) and the coldest (19 December 2010; daily air temperature $259.15 \mathrm{~K}$ ). Table 6 gives the mean measured and simulated temperatures of the debris for both days. On 25 November, temperature decreases from the surface of the debris toward the bottom, and the profile is reversed during the cold day (19 December). The fact that in both cases vertical temperature profiles (Fig. 11) and daily temperatures (Table 6) are well simulated gives confidence in the ability of the model to properly reproduce the day-to-day variations in the thermal conditions in the debris. Nevertheless, there are some discrepancies between observations and simulations. Mainly at the beginning of the study period, at -2.5 and $-5.0 \mathrm{~cm}$ simulated maximal temperatures often exceed the melting point, sometimes by more than $10 \mathrm{~K}$, although measured temperatures do not exceed $273.15 \mathrm{~K}$ at $-5 \mathrm{~cm}$ and are limited to $280 \mathrm{~K}$ at $-2.5 \mathrm{~cm}$. At $-5 \mathrm{~cm}$, the simulated daily amplitude is also somewhat overestimated compared with measurements.

The mean diurnal cycles over the study period (5 November to 30 December) of measured and simulated temperatures at various depths within the debris $(-2.5$, $-5.0,-7.5$ and $10 \mathrm{~cm}$ ) on Changri Nup Glacier are shown in Figure 12. A statistical summary is also presented in Table 7. The warming of the debris follows the diurnal cycle of incident solar radiation. The temperature at $-2.5 \mathrm{~cm}$ increases from 7:00 to 13:00 and decreases quickly until the sunset and then slowly but continuously until sunrise. In daytime, a warm front progressively propagates within the debris layer from the surface, with a delay of temperature maximum and attenuation of the diurnal thermal amplitude, more pronounced for deeper debris (Fig. 12a). At night, the opposite pattern is observed, as a cold front propagates into the debris. A comparison between Figure $12 \mathrm{a}$ and $\mathrm{b}$, and the statistical analysis in Table 7 shows that Crocus-DEB is able to consistently reproduce the thermal evolution of the debris, but tends to slightly 

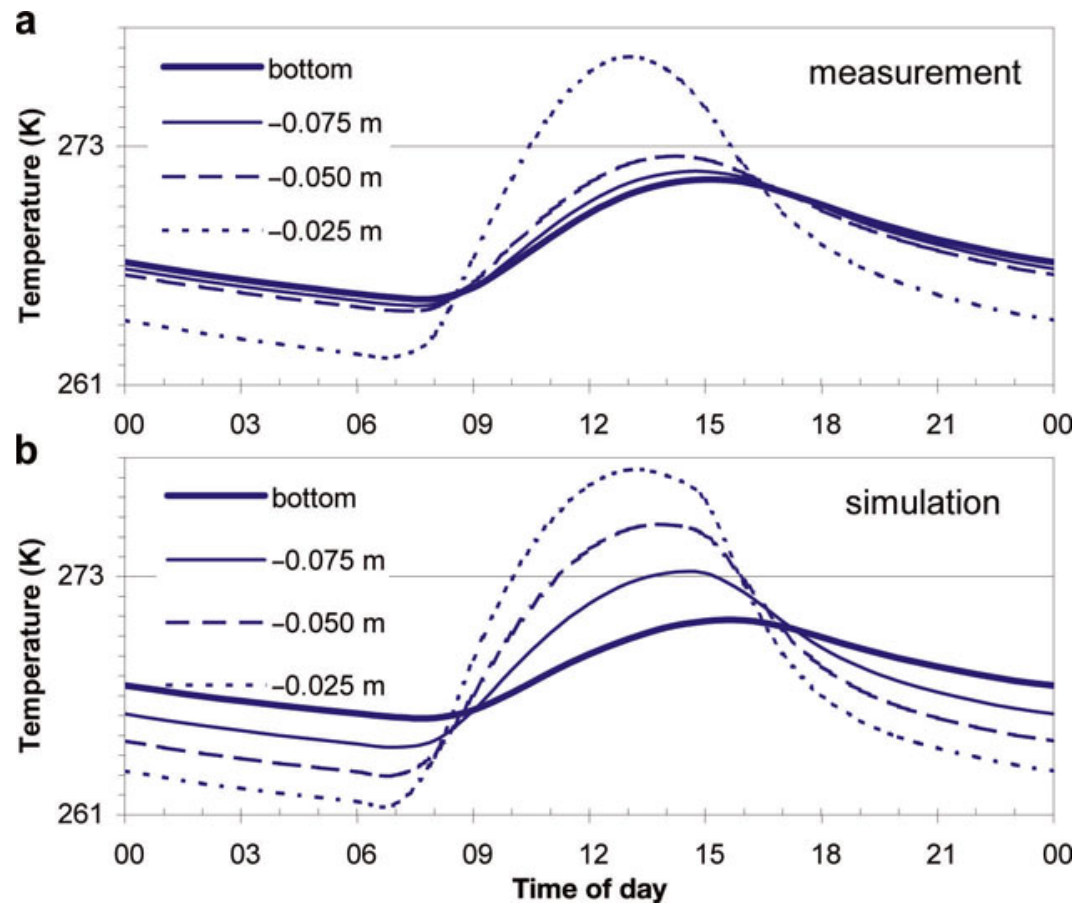

Fig. 12. Diurnal cycle of (a) measured and (b) simulated temperatures at Changri Nup Glacier at depths of (a) 2.5, (b) 5.0 , (c) 7.5 and (d) $10 \mathrm{~cm}$ (the ice/debris interface) within the natural $10 \mathrm{~cm}$ thick debris layer.

overestimate the diurnal amplitude at $-7.5 \mathrm{~cm}$ and at the bottom $(4.1$ and $2.9 \mathrm{~K}$, respectively).

\section{DISCUSSION}

\section{Ability of the model to simulate the specific processes driving the melting of debris-covered glaciers}

In this study, the snow model Crocus was adapted to deal with a debris layer as observed on debris-covered glaciers. Crocus-DEB is therefore a physically based model able to simulate the energy and mass fluxes across the ice/debris/ snow/atmosphere continuum.

To thoroughly test the performance of the model, CrocusDEB was applied to and calibrated on 4 and $15 \mathrm{~cm}$ thick debris layers, artificially poured over a seasonal alpine snow cover where meteorological forcing and snow conditions are continuously extensively measured, before being directly applied (without extra calibration) over a natural Nepalese debris-covered glacier. Over this glacier, we selected a dry period (no precipitation and debris exposed at the surface) in November and December 2011, with highly variable meteorological conditions between nights and days, and between the beginning (melting conditions encountered for a few hours in daytime) and the end (cold conditions and no melting) of the period (Fig. 12). On the whole, there is good agreement between observations and simulations, while considering the temporal evolution of the SWE above the ground or debris temperatures or heat fluxes at the bottom of the debris (Figs 8, 9 and 12; Tables 3, 4 and 6 ). This means that the main processes that control the melting of the underlying snow/ice layers below the debris are well simulated by the model, i.e. that the conflicting effect between the enhanced absorption of incoming solar radiation, due to the low albedo of the debris, and the insulating effect is well reproduced by the model. However, several discrepancies between measurements and simulations have also been shown, in particular regarding the magnitude of the hourly variations of temperature and heat flux within or at the bottom of the debris layer (e.g. Figs 9 and 12). Daily integrations of the heat flux at the bottom of the debris cover are well simulated at Col de Porte; we further note that, as soon as the temperature remains below the melting point throughout the day at the Changri Nup site, the agreement between measurements and simulations becomes almost perfect (Fig. 11d). It appears very likely that

Table 6. Observed and simulated profiles of internal temperatures within the debris layer on the warmest (25 November 2010) and coolest (19 December 2010) days of the simulation period at Changri Nup Glacier

\begin{tabular}{|c|c|c|c|c|}
\hline \multirow[b]{2}{*}{ Depth } & \multicolumn{2}{|c|}{25 Nov 2011} & \multicolumn{2}{|c|}{19 Dec 2011} \\
\hline & Measured & Simulated & Measured & Simulated \\
\hline $\mathrm{m}$ & K & K & K & K \\
\hline-0.025 & 272.3 & 272.8 & 264.0 & 263.7 \\
\hline-0.050 & 271.9 & 272.5 & 265.2 & 263.9 \\
\hline-0.075 & 271.6 & 272.2 & 265.3 & 264.2 \\
\hline Bottom & 271.6 & 271.7 & 265.5 & 264.7 \\
\hline
\end{tabular}


Table 7. Statistical summary of the diurnal cycles of the internal temperatures observed and simulated at Changri Nup Glacier within the natural $10 \mathrm{~cm}$ thick debris layer

\begin{tabular}{|c|c|c|c|c|c|}
\hline & & $\begin{array}{c}\text { Debris temperature } \\
\text { at }-0.025 \mathrm{~m}\end{array}$ & $\begin{array}{c}\text { Debris temperature } \\
\text { at }-0.050 \mathrm{~m}\end{array}$ & $\begin{array}{c}\text { Debris temperature } \\
\text { at }-0.075 \mathrm{~m}\end{array}$ & $\begin{array}{c}\text { Debris temperature } \\
\text { at bottom }\end{array}$ \\
\hline & & K & $\mathrm{K}$ & K & K \\
\hline \multirow{3}{*}{ Measured } & $\min$ & 262.6 & 264.9 & 265.2 & 265.5 \\
\hline & $\max$ & 277.7 & 272.7 & 271.9 & 271.5 \\
\hline & av. & 268.0 & 268.2 & 268.2 & 268.2 \\
\hline \multirow{3}{*}{ Simulated } & $\min$. & 261.7 & 263.2 & 264.6 & 266.0 \\
\hline & $\max$ & 278.5 & 275.8 & 273.3 & 270.9 \\
\hline & av. & 267.7 & 267.9 & 268.1 & 268.3 \\
\hline Mean deviation & & -0.23 & -0.28 & -0.06 & 0.07 \\
\hline $\mathrm{rms}$ & & 1.09 & 2.03 & 0.91 & 0.42 \\
\hline$r^{2}$ & & 0.99 & 0.90 & 0.95 & 0.99 \\
\hline
\end{tabular}

the discrepancies reported here stem from the inadequate handling of phase change and hydraulics within the debris. As indicated above, one key assumption of the model is that liquid water entering the debris layer is immediately transferred below it. In reality, even if it is very coarsely grained, the debris cover is able to retain liquid or ice water in interstitial spaces, often as a coating covering debris surfaces. Diurnal phase changes of the water film covering debris are likely to induce significant disturbances in the time variations of the energy budget of the debris within one day; however, as long as the liquid water flux is small, freeze/thaw cycles should compensate each other, leading to an insignificant net effect on the total energy transferred through the debris. This explains why, even if there are some discrepancies between hourly variations of the temperature or heat flux within or at the base of the debris layers, the net daily integrated simulated flux remains consistent with observations. Note that such an issue is not specific to Crocus-DEB and is likely to also have a significant impact on previously existing physically based debris-cover models (Nicholson and Benn, 2006; Reid and Brock, 2010). Various other reasons can be invoked to explain the observed discrepancies, including, for example, non-conductive processes within the debris cover, which were not accounted for in the present study (Nicholson and Benn, in press). More work is needed to incorporate a physically consistent phase-change and water percolation scheme within the debris in Crocus-DEB.

\section{Comparison with alternative models}

Besides the ability to simulate the inception, development and melt of a transient snowpack on top of a debris layer, which directly derives from the use of the detailed snowpack model Crocus, the main difference between Crocus-DEB and existing numerical models applied to the melt of debriscovered glaciers (Nicholson and Benn, 2006; Reid and Brock, 2010; Reid and others, 2012) is the explicit simulation of the temperature profile below the debris. Previous models are generally only applied during the melt season, and assume that the temperature at the base of the debris is the melt temperature. In Crocus-DEB, this hypothesis is relaxed, which allows us to simulate the surface energy and mass balance year-round. Numerical experiments were carried out to investigate the impact of this assumption on the surface energy balance. In the case of a thick debris cover $(15 \mathrm{~cm})$, the impact of this assumption during the melt season is limited, although it is detectable. When the debris thickness is lower $(4 \mathrm{~cm}$ in the tested example), even during the melt season the net heat flux through the debris is underestimated by a factor of two when the temperature profile below the debris is imposed to remain at the melting temperature. In this case, the artificial addition of energy to the below-debris snow layers exceeds the heat flux through the debris. In such a case, the adjustment in surface energy and mass-balance models of some of the physical properties not easily measured in the field, such as the effective thermal conductivity of the debris, may be prone to errors due to the compensation of an inadequate assumption on the basal temperature of the debris. We also note that this assumption, if implemented in algorithms used to map the physical properties of debris cover from remotely sensed thermal data, would lead to systematic errors in the retrieved properties of the debris, especially when the debris cover is thin (i.e. less than $\sim 15 \mathrm{~cm})$.

\section{An example of model application: a study of the critical thickness at CDP}

The ability of the model to represent the opposing effects of the debris cover, iconically summarized through the concept of the critical thickness (Østrem, 1959), was tested using model runs at CDP. Crocus-DEB runs were performed using the same method as described above for $\mathrm{TA}_{4}$ and $\mathrm{TA}_{15}$, but for a series of debris thickness values ranging from 1 to $30 \mathrm{~cm}$ in steps of $1 \mathrm{~cm}$. Moreover, three additional runs were done without debris. For these latter runs, the broadband albedo of all the initial snow layers (i.e. snow layers older than 8 February 2012) was forced to 0.4, 0.3 and 0.2, respectively. These runs mimic the temporal evolution of the surface energy and mass balance of debris-free glaciers with varying bare-ice albedo. The model was run from 8 February 2011 with identical snowpack properties below the debris and for the debris-free runs. The initial total SWE of the underlying snowpack or the debris-free snowpack was taken equal to $150.6 \mathrm{~kg} \mathrm{~m}^{-2}$. From these model runs, daily ablation rates integrated over various periods were computed, and the date of the total melt was extracted. These results are shown in Figure 13, which can be viewed as various flavours of so-called Østrem curves (Østrem, 1959; Reid and Brock, 2010). 

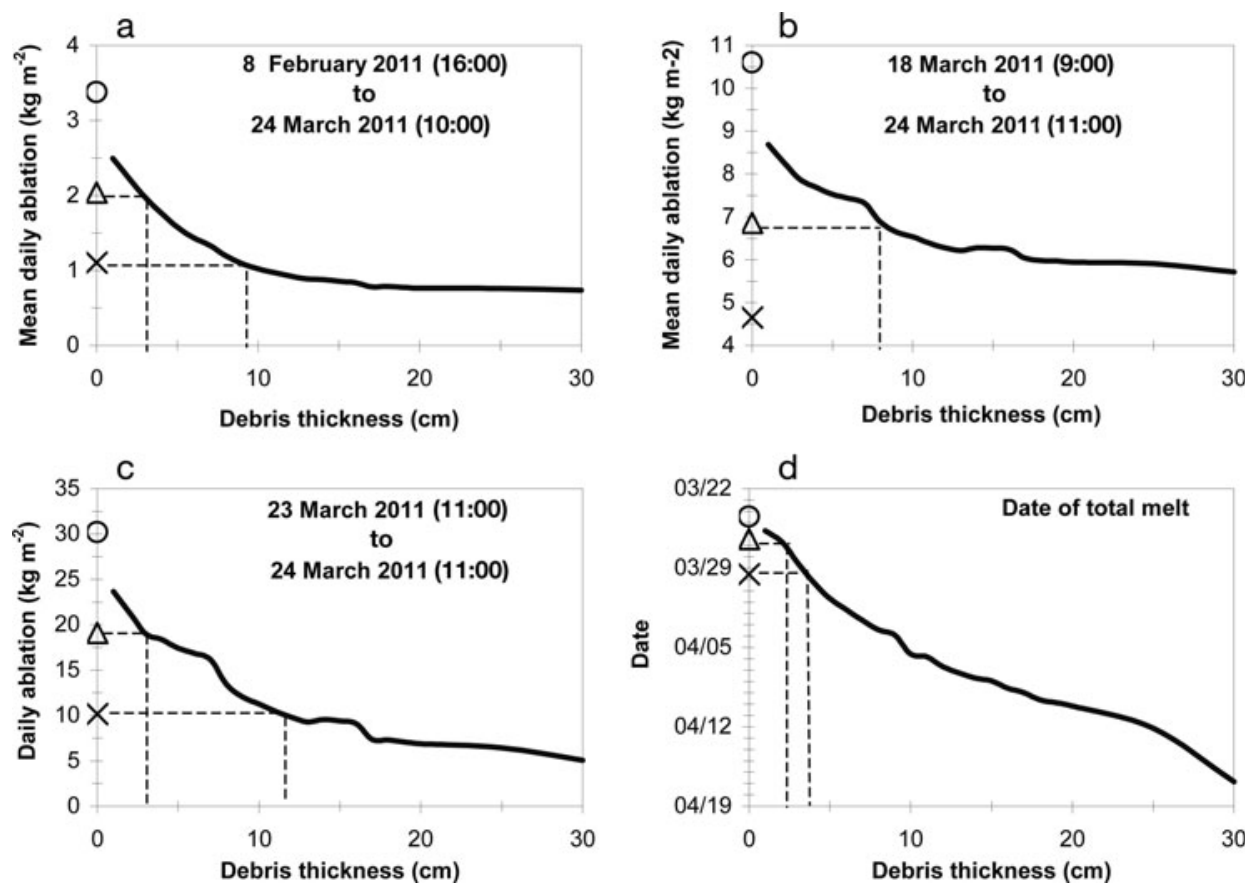

Fig. 13. Results of the Crocus-DEB simulations, using CDP model configuration and meteorological input data at CDP, of total SWE for a series of debris thickness values ranging from 1 to $30 \mathrm{~cm}$ in steps of $1 \mathrm{~cm}$ and for three debris-free runs characterized by a broadband albedo of the initial snowpack of 0.4 (crosses), 0.3 (triangles) and 0.2 (circles). (a-c) Integrated daily ablation rates over various periods of time; (d) date of total melt (with date format on axis $\mathrm{mm} / \mathrm{dd}$ )

Figure 13 confirms that, as expected, melting is accelerated for thinner debris layers, and slowed for thicker layers, in full agreement with the Østrem (1959) curve. Nevertheless, this artificial example illustrates several facts relevant to the concept of the critical thickness. In particular, significant variations in critical debris thickness may, in some cases, simply stem from a change in reference debris-free glacier albedo. In addition, the critical debris thickness computed can differ widely, depending on the period chosen, and in some cases it cannot even be defined (e.g. when the melt rate under the thinnest debris layer is lower than the melt rate in the debris-free area). This occurs in our case when the albedo of the debris-free area is of the same order of magnitude as the albedo of the debris. The dependence of critical debris thickness on meteorological conditions that we observed experimentally is also revealed by the numerical experiments, and confirms that this concept, while extremely powerful in explaining concisely the physical impact of debris covers on glacier energy and mass balance, should not be used further than for pedagogic purposes.

\section{CONCLUSION AND OUTLOOK}

In this study, we have introduced the physically based Crocus-DEB model able to simulate year-round the energy budget of the surface and the mass balance of debriscovered glaciers, taking into account not only snow layers that can deposit over the debris, but also the thermal evolution of the snow/debris/ice continuum without any assumption about the temperature at the base of the debris layer. The model was evaluated against data from a series of field experiments using an artificial debris-covered snowpack, as well as in situ data from the debris-covered glacier Changri Nup, in the Himalaya. The model performs well in terms of surface energy balance and net daily heat flux through the debris, and can be used at the spatial scale of the whole glacier to study the impact of the debris-cover layer on the glacier energy and mass balance. Improving the handling of vertical water transfer and phase changes within the debris cover is the next step of model development, which will improve the time evolution of the temperature and heat flux within and at the boundaries of the debris cover. The model was also used to briefly explore the concept of a critical debris thickness. The critical debris thickness depends strongly on the reference debris-free glacier, in particular its ice broadband albedo, and on the meteorological conditions, implying that defining a sole value of the critical debris thickness for a given glacier may be misleading.

\section{ACKNOWLEDGEMENTS}

We thank J.-M. Panel, B. Lesaffre and D. Poncet for support during the field experiment at Col de Porte, and J.-M. Willemet for help in developing the model. This work was supported by the French Service d'Observation GLACIOCLIM and the Italian Consortium Ev-K2-CNR, which provided all the logistical support on Changri Nup Glacier. Pyramid and Ev-K2-CNR staff members are especially acknowledged for their help and their participation in the fieldwork in Nepal. Funding from INSU-LEFE and Agence Nationale de la Recherche (ANR-09-CEP-005-01/ PAPRIKA) is gratefully acknowledged. We thank the Scientific Editor, T. Moelg, T. Reid and an anonymous reviewer for very useful comments and suggestions.

\section{REFERENCES}

Barnett TP, Adam JC and Lettenmaier DP (2005) Potential impacts of a warming climate on water availability in snow-dominated regions. Nature, 438(7066), 303-309 (doi: 10.1038/ nature04141) 
Benn DI, Kirkbride MP, Owen LA and Brazier V (2003) Glaciated valley landsystems. In Evans DJA ed. Glacial landsystems. Arnold, London, 372-406

Bolch T and 10 others (2012) The state and fate of Himalayan glaciers. Science, 336(6079), 310-314 (doi: 10.1126/science. 1215828)

Bookhagen B and Burbank DW (2010) Toward a complete Himalayan hydrological budget: spatiotemporal distribution of snowmelt and rainfall and their impact on river discharge. J. Geophys. Res., 115(F3), F03019 (doi: 10.1029/2009JF001426)

Bouilloud L and Martin E (2006) A coupled model to simulate snow behavior on roads. J. Appl. Meteorol. Climatol., 45(3), 500-516 (doi: 10.1175/JAM2350.1)

Brun E, Martin E, Simon V, Gendre C and Coléou C (1989) An energy and mass model of snow cover suitable for operational avalanche forecasting. J. Glaciol., 35(121), 333-342

Brun E, David P, Sudul M and Brunot G (1992) A numerical model to simulate snow-cover stratigraphy for operational avalanche forecasting. J. Glaciol., 38(128), 13-22

Conway H and Rasmussen LA (2000) Summer temperature profiles within supraglacial debris on Khumbu Glacier Nepal. IAHS Publ. 264 (Symposium at Seattle 2000 - Debris-Covered Glaciers), 89-97

Dumont M, Durand Y, Arnaud Y and Six D (2012) Variational assimilation of albedo in a snowpack model and reconstruction of the spatial mass-balance distribution of an alpine glacier. J. Glaciol., 58(207), 151-164 (doi: 10.3189/2012JoG11J163)

Dyurgerov MB and Meier MF (2005) Glaciers and the changing Earth system: a 2004 snapshot. (INSTAAR Occasional Paper 58) Institute of Arctic and Alpine Research, University of Colorado, Boulder, CO

Gerbaux M, Genthon C, Etchevers P, Vincent C and Dedieu JP (2005) Surface mass balance of glaciers in the French Alps: distributed modeling and sensitivity to climate change. J. Glaciol., 51(175), 561-572 (doi: 10.3189/172756505781829133)

Hock R (2003) Temperature index melt modelling in mountain areas. J. Hydrol., 282(1-4), 104-115 (doi: 10.1016/S0022-1694 (03)00257-9)

Immerzeel WW, Van Beeke LPH and Bierkens MFP (2010) Climate change will affect the Asian water towers. Science, 328(5984), 1382-1385 (doi: 10.1126/science.1183188)

Kääb A, Berthier E, Nuth C, Gardelle J and Arnaud Y (2012) Contrasting patterns of early twenty-first-century glacier mass change in the Himalayas. Nature, 488(7412), 495-498 (doi: 10.1038/nature11324)

Kaser G, Cogley JG, Dyurgerov MB, Meier MF and Ohmura A (2006) Mass balance of glaciers and ice caps: consensus estimates for 1961-2004. Geophys. Res. Lett., 33(19), L19501 (doi: 10.1029/2006GL027511)

Kayastha RB, Takeuchi Y, Nakawo M and Ageta Y (2000) Practical prediction of ice melting beneath various thickness of debris cover on Khumbu Glacier, Nepal using a positive degree-day factor. IAHS Publ. 264 (Symposium at Seattle 2000 - DebrisCovered Glaciers), 71-81

Lejeune Y (2009) Apports des modèles de neige CROCUS et de sol ISBA à l'étude du bilan glaciologique d'un glacier tropical et du bilan hydrologique de son bassin versant. (PhD thesis, Université Joseph Fourier)

Lejeune $Y$ and 7 others (2007) Melting of snow cover in a tropical mountain environment in Bolivia: processes and modeling. J. Hydromet., 8(4), 922-937 (doi: 10.1175/JHM590.1)

Loomis SR (1970) Morphology and ablation processes on glacier ice. Assoc. Am. Geogr. Proc., 2, 88-92

Martin E and Lejeune $Y$ (1998) Turbulent fluxes above the snow surface. Ann. Glaciol., 26, 179-183

Mattson LE, Gardner JS and Young GJ (1993) Ablation on debris covered glaciers: an example from the Rakhiot Glacier, Punjab, Himalaya. IAHS Publ. 218 (Symposium at Kathmandu 1992 Snow and Glacier Hydrology), 289-296

Mool PK, Bajracharya SR and Joshi SP (2001) Inventory of glaciers, glacial lakes and glacial lake outburst floods: monitoring and early warning systems in the Hindu KushHimalayan region, Nepal. International Centre for Integrated Mountain Development with United Nations Environment Programme/Regional Resource Centre for Asia and the Pacific, Kathmandu

Moribayashi S and Higuchi K (1977) Characteristics of glaciers in Khumbu region and their recent variations. Seppyo, J. Jpn. Soc. Snow Ice, 39, 3-6

Morin S and 6 others (2012) An 18-yr long (1993-2011) snow and meteorological dataset from a mid-altitude mountain site (Col de Porte, France, $1325 \mathrm{~m}$ alt.) for driving and evaluating snowpack models. Earth Syst. Sci. Data, 4(1), 13-21 (doi: 10.5194/essd-413-2012)

Nicholson L and Benn DI (2006) Calculating ice melt beneath a debris layer using meteorological data. J. Glaciol., 52(178), 463-470 (doi: 10.3189/172756506781828584)

Nicholson L and Benn DI (in press) Properties of natural supraglacial debris in relation to modelling sub-debris ice ablation. Earth Surf. Process. Landf. (doi: 10.1002/esp.3299)

Østrem G (1959) Ice melting under a thin layer of moraine, and the existence of ice cores in moraine ridges. Geogr. Ann., 41(4), 228-230

Reid TD and Brock BW (2010) An energy-balance model for debris-covered glaciers including heat conduction through the debris layer. J. Glaciol., 56(199), 903-916 (doi: 10.3189/ 002214310794457218)

Reid TD, Carenzo M, Pellicciotti F and Brock BW (2012) Including debris cover effects in a distributed model of glacier ablation. J. Geophys. Res., 117(D18), D18105 (doi: 10.1029/ 2012JD017795)

Scherler D, Bookhagen B and Strecker MR (2011) Spatially variable response of Himalayan glaciers to climate change affected by debris cover. Nature Geosci., 4(3), 156-159 (doi: 10.1038/ ngeo1068)

Vionnet V and 7 others (2012) The detailed snowpack scheme Crocus and its implementation in SURFEX v7.2. Geosci. Model Dev., 5(3), 773-791 (doi: 10.5194/gmd-5-773-2012)

Willemet J-M (2010) The snow cover model CROCUS. User's guide version 2.4. Météo France/Centre National de Recherches Météorologiques/Centre d'Etudes de la Neige, Saint-Martin$d^{\prime}$ Hères 